\title{
Initialized Earth System prediction from subseasonal to decadal
}

\section{timescales}

Gerald A. Meehl ${ }^{1 \dagger}$, Jadwiga H. Richter ${ }^{1}$, Haiyan Teng ${ }^{1}$, Antonietta Capotondi ${ }^{2,3}$, Kim $\mathrm{Cobb}^{4}$, Francisco Doblas-Reyes ${ }^{5,6}$, Markus G. Donat ${ }^{5}$, Matthew H. England ${ }^{7}$, John C. Fyfe $^{8}$, Weiqing Han ${ }^{9}$, Hyemi Kim ${ }^{10}$, Ben P. Kirtman ${ }^{11}$, Yochanan Kushnir ${ }^{12}$, Nicole S. Lovenduski ${ }^{9}, 13$, Michael E. Mann ${ }^{14,15}$, William J. Merryfield ${ }^{8}$, Veronica Nieves ${ }^{16}$, Kathy Pegion ${ }^{17}$, Sara C. Sanchez ${ }^{18}$, Adam A. Scaife ${ }^{19,20}$, Doug Smith ${ }^{19}$, Aneesh C. Subramanian $^{9}$, Lantao Sun ${ }^{21}$, Diane Thompson ${ }^{22}$, Caroline C. Ummenhofer ${ }^{23}$, ShangPing $\mathrm{Xie}^{24}$

1. Climate and Global Dynamics Laboratory, National Center for Atmospheric Research, Boulder, CO, USA

2. Cooperative Institute for Research in Environmental Sciences, University of Colorado, Boulder, CO, USA

3. NOAA Physical Sciences Laboratory, Boulder, CO, USA

4. School of Earth and Atmospheric Sciences, Georgia Institute of Technology, Atlanta, Georgia, USA

5. Barcelona Supercomputing Center and ICREA, Barcelona, Spain

6. Institució Catalana de Recerca i Estudis Avançats, Barcelona, Spain

7. Climate Change Research Centre, University of New South Wales, Sydney, NSW, Australia

8. Canadian Centre for Climate Modeling and Analysis, Environment and Climate Change, Victoria, BC, Canada

9. Department of Atmospheric and Oceanic Sciences, University of Colorado, Boulder, $\mathrm{CO}, \mathrm{USA}$

10. School of Marine and Atmospheric Sciences, Stony Brook University, Stony Brook, New York, USA

11. Rosenstiel School for Marine and Atmospheric Science, University of Miami, Miami, FL, USA

12. Lamont Doherty Earth Observatory, Columbia University, Palisades, NY, USA

13. Institute of Arctic and Alpine Research, University of Colorado, Boulder, CO, USA

14. Dept. of Meteorology \& Atmospheric Science The Pennsylvania State University, State College, PA, USA

15. Earth \& Environmental Systems Institute, Pennsylvania State University, State College, PA, USA

16. Image Processing Laboratory, University of Valencia, Valencia, Spain

17. Department of Atmospheric Oceanic and Earth Sciences, George Mason University, Fairfax, VA, USA

18. Joint Institute for the Study of the Atmosphere and Ocean, University of Washington, Seattle, WA, USA

19. Hadley Centre, Exeter, U.K.

20. College of Engineering, Mathematics and Physical Sciences, University of Exeter, Exeter, U.K. 
21. Department of Atmospheric Science, Colorado State University, Ft. Collins, CO, USA

22. Department of Geosciences, University of Arizona, Tucson, AZ, USA

23. Woods Hole Oceanographic Institution, Woods Hole, MA, USA

24. Scripps Institution of Oceanography, La Jolla, CA USA

†email:meehl@ucar.edu
Abstract

Initialized Earth System predictions are made by starting a numerical prediction model in a state as consistent as possible to observations and running it forward in time for up to 10 years. Skilful predictions at time slices from subseasonal to seasonal (S2S), seasonal to interannual (S2I) and seasonal to decadal (S2D) offer information useful for various stakeholders, ranging from agriculture to water resource management to human and infrastructure safety. In this Review, we examine the processes influencing predictability, and discuss estimates of skill across S2S, S2I and S2D timescales. There are encouraging signs that skilful predictions can be made: on $\mathrm{S} 2 \mathrm{~S}$ timescales, there has been some skill in predicting the Madden-Julian Oscillation and North Atlantic Oscillation; on S2I, in predicting the EI Niño-Southern Oscillation; and on S2D, in predicting ocean and atmosphere variability in the North Atlantic region. However, challenges remain, and future work must prioritize reducing model error, more effectively communicating forecasts to users, and increasing process and mechanistic understanding that could enhance predictive skill and, in turn, confidence. As numerical models progress towards Earth System models, initialized predictions are expanding to include prediction of sea ice, air 
pollution, and terrestrial and ocean biochemistry that can bring clear benefit to society and various stakeholders.

\section{Key points}

- Initialization methods vary greatly across different prediction timescales, creating difficulties for seamless prediction.

- Model error and drift limit predictability across all timescales. Although higher resolution models show promise in reducing these errors, improvements in physical parameterizations are needed to improve predictability.

- The effects of land processes, interactions across various ocean basins and the role of stratospheric processes in predictability are not well understood.

- Predictability on seasonal to decadal timescales is largely associated with predictability of the major modes of variability in the atmosphere and the ocean.

- Evolution of Earth System models will lead to predictability of more societalrelevant variables spanning multiple parts of the Earth System.

\section{[H1] Introduction}

There has been an increasing desire for climatic information on timescales from weeks to months, seasons and years. Such information offers clear benefits to society and various stakeholders alike. For instance, prediction of the hydroclimate could allow for better water resource management and improved agricultural maintenance, 
whereas temperature and wind predictions could provide critical information for infrastructure planning and expected energy consumption. To obtain this climatic information, initialized predictions on various near-term timescales must be used. Initialized Earth System prediction describes a suite of climate model simulations wherein the starting conditions are set as close to observations as possible and the

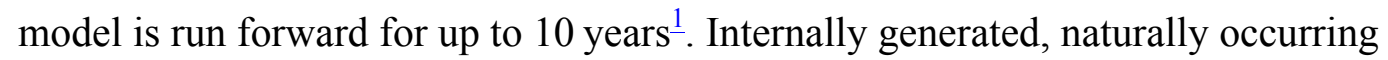
variability is therefore considered a key aspect of these time-evolving climate predictions ${ }^{2}$. They differ from uninitialized simulations - or climate change projections - where internal variability is removed through ensemble averaging, and focus is instead given to quantifying the effects of external forcing such as anthropogenic greenhouse gases ${ }^{3,4}$.

Given the duration of simulations, initialized predictions span various timescales (Fig. 1a): subseasonal to seasonal ( $\mathrm{S} 2 \mathrm{~S} ; \sim 2$ weeks -2 months) $)^{5,6}$, seasonal to interannual (S2I; 2-12 months) ${ }^{7}$ and seasonal to decadal (S2D; 3 months-10 years) ${ }^{1,2}$. In each case, efforts have focused on climate phenomena that also operate on similar timescales. For example, S2S research has concentrated on the Madden-Julian Oscillation (MJO) and sudden stratospheric warmings (SSWs); S2I on the El NiñoSouthern Oscillation (ENSO), North Atlantic Oscillation (NAO), Indian Ocean Dipole (IOD), Southern Annular Mode (SAM) and Quasi-Biennial Oscillation (QBO); and S2D on slowly evolving oceanic processes such as Pacific decadal variability (PDV) and Atlantic multi-decadal variability (AMV).

Distinct communities have therefore formed to coordinate research and perform initialized predictions on each timescale. Efforts such as the S2S Prediction Project and Database ${ }^{5}$ and the Subseasonal Experiment $\left(\mathrm{SubX}^{6}\right)$ emerged for S2S; the North American Multi-Model Ensemble ${ }^{7}$, the Asia-Pacific Economic Cooperation (APEC) 
118 Climate Center (APCC), and the Copernicus Climate Change Service for S2I; and sets

119 of hindcasts and predictions as part of the Coupled Model Intercomparison Project

120 phase 5 (CMIP5) ${ }^{1,2}$ and CMIP6 (ref. ${ }^{-}$) for S2D.

121 Although these communities are often separate, however, they all rely on similar methodologies (Table 1; see Supplementary Tables 1-3). Thus, there is potential for 'seamless prediction’ ${ }^{,}$, whereby one framework can be used to address prediction across all timescales, with skill increasingly associated with external forcing as simulations progress $^{10}$ (Fig. 1b). Yet, in practice, community differences with regards to initialization frequency, for example, make seamless prediction challenging $\stackrel{1,2}{2}$. In this Review, we bring together research on initialized predictions on timescales of weeks to years. We begin by outlining current methodologies for initialized predictions, incorporating discussion of the process, ensemble size, verification and prediction skill. We subsequently outline prediction on S2S, S2I and S2D timescales, before discussing priorities for future research that will increase the feasibility for seamless prediction.

135 S2I research using initialized prediction has been taking place since the late 1980s

136 (ref..$^{11}$ ). In contrast, it was not until 20 years later that initialized S2D climate

137 predictions began, in turn, initiating a rapid acceleration of research from which

138 operational systems are now routinely produced ${ }^{12}$. We begin by describing the

139 process of initialized prediction, focusing on the methodological aspects involving

140 forecast verification and measures of prediction skill (the level of agreement between

141 an initialized prediction and the observed state it is meant to predict). 


\section{[H2] Process of initialized prediction}

144 Predictions for S2S, S2I and S2D timescales, ranging from weeks to years, use

145 numerical models with components of (at least) atmosphere, ocean, land and sea ice

146 that are started from a particular observed state. The process of bringing the model

147 components into close correspondence with that observed state is termed

148 initialization, and predictions that are started from such observed states are referred to

149 as initialized predictions. There are currently many activities taking place in the S2S,

150 S2I and S2D communities with regards to initialized prediction, with key differences

151 amongst centres regarding how models are used (Table 1; see Supplementary Tables

$152 \quad 1-3)$.

153 One key difference between the subseasonal and longer timescale systems is the

154 origin of the model. Many S2S (and some S2I) prediction systems originate in the

155 numerical weather prediction community. As such, they tend to have the highest

156 horizontal resolution in the atmosphere, largely $\sim 0.25-0.5^{\circ}$ (Table 1). Atmospheric

157 initialization in these numerical weather prediction-derived models uses data

$158 \operatorname{assimilation}^{\underline{13}}$, such as $3 \mathrm{D}$ variational assimilation (as in the CMA model). Moreover,

159 to produce the initial perturbations for ensemble generation, they sometimes use data

160 assimilation with an ensemble Kalman filter ${ }^{14}$ (as in the ECCC model) or singular

161 vectors $^{15}$ (as in the JMA model). In comparison, most S2I, and all but one S2D,

162 prediction systems are based on climate or Earth System models (ESMs) previously

163 used for IPCC climate projections. In these cases, the majority of models have a

164 horizontal resolution of $\sim 0.5-1^{\circ}$ (Table 1$)$.

165 In addition to differences in the models and their resolution across prediction

166 timescales, contrasts are also evident in the components that are initialized and the 
degree of coupling between Earth System components. In S2S predictions, for example, coupling between the atmosphere, ocean, land and sea ice is not considered crucial (Fig. 1a). As such, only a small number of models initialize the ocean and employ atmosphere-ocean coupling, but the majority initialize land surface conditions (Supplementary Table 1). For S2D predictions, however, oceanic processes are vital and, as a result, all models initialize the ocean and have at least partial coupling with the atmosphere and sea ice; only a fraction initialize the atmosphere and land surface (Supplementary Table 3). As S2I falls in the time window where predictability comes from all Earth System components (Fig. 1a), care is typically taken to initialize each of them.

Atmospheric initialization is often achieved by interpolating an existing analysis to the model grid and generating an ensemble spread using the random field perturbation $\operatorname{method}^{16}$ (as in CESM1 for S2S), the lagged ensemble method ${ }^{17}, \underline{18}$ (as in CCSM3) or nudging to reanalyses in coupled mode ${ }^{19}$ (as in the CCCma model). Various approaches have also been used to initialize the ocean state, including a hindcast spinup in an ocean forced by observed atmospheric conditions ${ }^{20}$, nudging the ocean model to some observed ocean state ${ }^{21}$ or using full ocean data assimilation ${ }^{22}$. Land variables are initialized either by assimilation of land observations ${ }^{23}$ or by running an offline land-only model that is forced with observed atmospheric conditions ${ }^{24}$. The initialization strategy also differs between the shorter and longer-term prediction models. All S2S and S2I prediction models use full fields (such as sea surface temperature (SST)). By contrast, about half of the S2D modes use anomaly initialization, meaning an initial condition is constructed by adding observed (or reanalysis) anomalies to the model's climatology in order to minimize initialization shock and model drift $\underline{25,26,27}$. 
As individual model components are often initialized in different ways, there is frequently no coupling between initial conditions for various parts of the Earth System, thereby creating an imbalance in the initial state of the model. New methodologies, such as weakly coupled and strongly coupled data assimilation, offer promising approaches to reduce initialization shock and imbalance in the model ${ }^{28}$. In the weakly coupled approach, the assimilation is applied to each of the components of the coupled model independently, whereas interaction between the components is provided by the coupled forecasting system ${ }^{28}$. In the strongly coupled method, however, assimilation is applied to the full Earth System state simultaneously, treating the coupled system as a single integrated system $^{28}$.

There are currently very few modelling centres that have been able to apply seamless prediction owing to numerous practical aspects (including the initialization method, initialization frequency, number of ensemble members, among others). The most seamless system is currently operated by the UK Met Office, which is providing S2S, S2I and S2D forecasts operationally using almost identical configurations of the model for all prediction systems ${ }^{29}$. NCAR, although not an operational centre, is also using the same models, CESM1 and CESM2, to generate S2S, S2I and S2D hindcasts (and predictions for research purposes) using the same modelling framework, although at this time initialization details vary among the three prediction systems.

\section{[H2] Ensemble size}

Ensemble size is an important aspect determining predictive skill and reliability. In most prediction systems, ensemble sizes typically range between 10 and 50 (Table 1). There is potential to increase the number of ensembles by combining those from multiple systems $s^{30}$ or time-lagged ensembles ${ }^{31}$, or using other techniques such as 
217 subsampling $\underline{32, \underline{33}}$ to improve the ensemble properties. Typically, the more ensemble

218 members, the higher the anomaly correlation coefficient (ACC), a measure of

219 prediction skill. For example, on S2S timescales, the ACC of global surface air

220 temperature over land is $\sim 0.29$ when using only 4 CESM1 hindcast ensemble

221 members $\frac{34}{}$, increasing to $\sim 0.33$ for 8 members and $\sim 0.36$ for 16 members (Fig. 2a).

222 Large ensembles are also advantageous for improving seasonal prediction skill of the

$223 \mathrm{NAO}^{35}$, including on S2D timescales $\stackrel{33,36}{ }$. For example, ACC values are $\sim 0.6$ for an

224 average of years $2-8$ when using 40 ensemble members $\frac{37}{}$ (Fig. 2b). Further increases

225 in multi-year NAO skill with an ACC of 0.8 are possible with a lagged ensemble of

226 several hundred members ${ }^{33}$ as a result of the modelled signal to noise ratio being too

227 small.

228 There are consequences and trade-offs in terms of computing costs when using more

229 ensemble members. For instance, an S2S reforecast could run 16 years $(\mathrm{SubX}) \times 4$

230 members $\times 2$ months long $\times$ weekly start dates for $\sim 600$ model years; an S2I example

231 could run 30 years $\times 9$ members $\times 1$ year long $\times 4$ start dates per year for

$232 \sim 1,000$ model years; and an S2D example (DCPP) could run 60 years $\times 10$

233 members $\times 10$ years long for $\sim 6,000$ model years.

234

235 [H2] Verification using observations

236 A key element of initialized prediction is having a solid understanding of the climate

237 phenomena that are being predicted. Analyses of observations in comparison with the

238 model simulations are thus required. On S2S and S2I timescales, the observational

239 record provides a good source of data to verify initialized hindcasts. For example,

240 observations cover roughly 30 ENSO events and as many as 300 MJO cycles. 
However, these data have their limitations. For instance, 3D observations of the atmosphere and ocean are desired for prediction verification, for understanding of

243 processes and mechanisms, and for initialization of the predictions in the first place ${ }^{38}$.

244 Yet such 3D gridded data are limited to the period of the satellite record (dating from 245 the late 1970s) and to reanalyses that assimilate all available observations. Moreover, 246 although several ENSO (and similar timescale) events have been observed, these can 247 exhibit different expressions ${ }^{39}$ and undergo large decadal to millennial

248 variations $\underline{40,41,42}^{\underline{42}}$, requiring a long observational record to perform robust analyses.

249 Researchers in the field of initialized Earth System prediction on S2D timescales

250 often cite the short observational record as a factor inhibiting understanding. For

251 example, with reliable observations limited to the latter half of the twentieth

252 century $\frac{43}{}$, only approximately three PDV or AMV transitions have occurred by which

253 to compare predictions. Although some observations are available earlier in the

254 twentieth century, these are sparse and reanalyses are highly uncertain, making

255 consistent comparisons of prediction skill between the pre and post-satellite eras

256 difficult. Added to that, subsurface ocean observations and critical state atmospheric

257 variables (such as surface winds) are crucial to understanding slow variations in the

258 climate system ${ }^{44}$, but such observations also have a very short duration. Moreover, it

259 is also difficult to objectively separate forced (natural and anthropogenic) and internal

260 decadal to multi-decadal climate variability, adding further challenges for S2D

261 prediction verification and triggering debate on best practices for signal

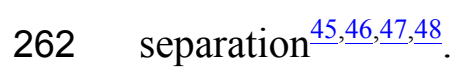

263 Nevertheless, efforts are underway to improve methodological approaches and data

264 provisions for prediction verification. The crucial need for better observations of the 
full depth of the ocean have started to be addressed by Argo floats, first for the upper

Proxy-based reconstructions are also increasingly available, shedding light on processes associated with interannual and decadal timescales of variability $\frac{51}{}$ beyond that possible by instrumental observations. Indeed, the particular limitations of instrumental data length and coverage for verification of S2D predictions have pointed to palaeoclimate reconstructions - using trees, corals and speleothems — to

273 extend observations and provide further realizations of decadal

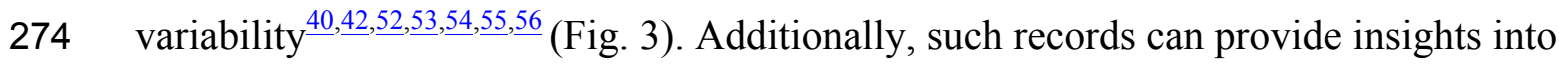
275 the physical mechanisms associated with this variability, including westerly wind 276 anomalies $\frac{51}{}$, upwelling, gyre circulation ${ }^{57}$ and links among major modes of 277 variability $\frac{58}{}$. Together with further advances in palaeoclimate research — including

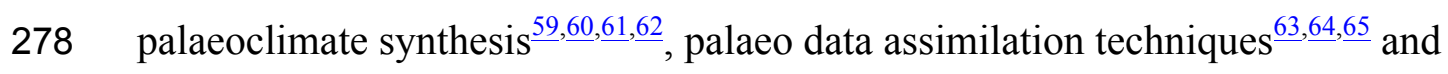
279 development and expansion of proxy system models and toolboxes $\underline{\underline{66}, \underline{67}}$ 280 palaeoclimate data will not only help with the verification of climate model simulations, particularly on the S2D timescale, but also provide context for initialized

282 predictions by providing insights into the timescales of variability beyond the 283 instrumental record.

\section{[H2] Bias correction and prediction skill}

286 To account for model drifts and biases, the skill of initialized predictions is typically

287 evaluated in terms of forecast time-dependent anomalies that are departures from

288 some measure of mean climate. However, a prediction will drift rapidly from the 289 initial observed state towards its own climatology owing to model error. These drifts 
start almost immediately in a prediction, and by lead year 1 are already considerable

291 (Fig. 4).

292 The calculation of anomalies and correction of model biases are addressed together,

293 typically by calculating and removing the model climatology. For S2S predictions, the

294 common methodology is to calculate a lead time-dependent model climatology from a

295 set of hindcasts and to compute anomalies from this climatology. However, such a

296 procedure is complicated owing to the inhomogeneous nature of current subseasonal

297 prediction systems ${ }^{6}$. The climatology for S2I predictions is similarly accomplished by

298 averaging over all years of the hindcast for a particular start time and lead or target

299 time $\frac{68}{}$, thereby assuming stationarity of biases and drifts in the predictions.

300 For S2D predictions, model drift is acute and is addressed by multiple approaches for

301 computing anomalies (Fig. 4). One method is to calculate the model climatology of

302 drifts from hindcasts over a prediction period of interest (for example, the average of

303 lead years 3-7) and, then, subtract that climatology from each prediction for years 3-7

304 (ref. $\left.\frac{69}{}\right)$; this approach works well for short timescale predictions where externally

305 forced trends are less of a factor, but can be problematic for longer timescales. An

306 alternative method is to compute a mean time-evolving drift from a set of hindcasts,

307 subtract that mean drift from a prediction and compute anomalies as differences from

308 the drift-adjusted prediction and time period (such as the previous 15-year average)

309 immediately prior to the prediction ${ }^{70}$. This alternative approach better reduces the

310 effects of an externally forced trend, but raises the issue of how great a role the recent

311 observed period should play in prediction verification. When long-term trends in the

312 hindcasts differ from observations, a further method is to correct biases in the trends

313 in addition to those in the mean model climatology over the hindcast period ${ }^{71}$,

314 although such an approach can yield an overestimation of the skill of the system. 
315 Models can also underestimate the magnitude of predictable signals relative to

316 unpredictable internal variability, especially at seasonal and longer timescales in the

317 extratropical North Atlantic sector ${ }^{33}$. This underestimation leads to the counter-

318 intuitive implication that models are better at predicting the real climate variability

319 than they are at predicting themselves, a phenomenon termed the 'signal to noise

320 paradox', when observed signal to noise ratios are larger than those in models ${ }^{72}$.

321 Given that such features also occur in uninitialized climate simulations of the

322 historical period $\stackrel{73,74}{ }$, and potentially in modelled responses to volcanoes and solar

323 variations $\frac{72}{}$, they are not believed to arise from initialization itself. As a result of the

324 signal to noise paradox, it is necessary to take the mean of a very large ensemble to

325 extract the predictable signal and then adjust its variance $\mathrm{e}^{33}$.

326 Although discrepancies between signal to noise measures in models and observations

327 highlight an important model deficiency, they also imply an optimistic potential to use

328 adjusted climate model outputs to predict the observed system $\underline{\underline{33}, \underline{36}}$. Additionally, there

329 has been growing interest in the influence of decadal variability on the predictability

330 and skill of seasonal forecasts ${ }^{75}$. Sometimes, the impact of this variability can obscure

331 the gradual skill improvements that are found from advancing the science and

332 modelling $\frac{76}{}$.

333 Clearly, a major challenge for initialized prediction at any timescale is the mean drift

334 of the model away from its initialized state to its preferred systematic error state

335 (Fig. 4). All of the efforts at bias adjustment and drift correction arise from this

336 fundamental characteristic of model error, but improvements in initialized prediction

337 require increased understanding of the processes and mechanisms at work in the

338 climate system in order to reduce model error. 


\section{[H1] S2S initialized predictions}

341 All initialized predictions start with a particular observed state that could contribute to

342 some combination of externally forced and internally generated variability. However,

343 owing to the relatively short timescales, subseasonal (S2S) predictability is largely an

344 initial value problem in which the atmosphere, ocean, land and sea ice contribute to

345 prediction skill through their memory of the initial state, and not external forcing

346 (Fig. 1). Considerable resources are therefore allocated to initialization of atmosphere

347 and land, including generation of ensemble spread. Ocean initialization and coupling

348 are additionally important, especially in tropical regions, where sources of

349 predictability can come from modes of variability such as the $\mathrm{MJO}^{6,77}$, as well as the

350 stratosphere, both of which are now discussed.

\section{[H2] Modes of variability}

353 The MJO is recognized as one of the leading sources of S2S predictability ${ }^{78}$ owing to

354 the strong interaction between the tropics and extratropics on subseasonal

355 timescales $^{79}$. For example, forecast models involved in the SubX and the S2S

356 Prediction Project can predict the MJO skilfully up to 4 weeks,$\underline{5,80,81}$. Furthermore,

357 skill has been shown in predicting the MJO in a multi-model framework consisting of

358 six SubX models for week 3 predictions averaged over days 15-21 (ref. ${ }^{6}$ ) (Fig. 5),

359 whereby most reproduce the eastward propagation of outgoing long-wave radiation

360 anomalies. Some models, however, have difficulty in simulating the propagation of

361 the MJO across the Maritime Continent (eastward of $120^{\circ} \mathrm{E}$ ), the so-called Maritime

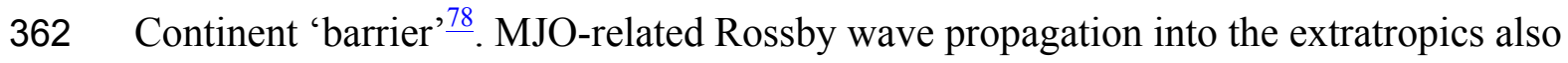

363 provides predictability for extreme events such as storm tracks $\frac{82}{}$, atmospheric

364 rivers $\underline{83}$ and tornadoes $\stackrel{84}{ }$. 
365 S2S predictability is also influenced by the NAO (itself influenced by ENSO ${ }^{85}$ ), sea 366 ice and the stratosphere ${ }^{86}$, which has a bearing on extremes in large regions of Europe 367 and North America. Using the NCEP Climate Forecast System version 2 (CFSv2) and 368 the Met Office Global Seasonal forecast System 5 (GloSea5), it has been suggested 369 that the NAO exhibits predictability to at least several months ahead $\underline{35, \underline{87}, \underline{88}}$. Indeed, all 370 SubX models demonstrate significant NAO skill at week 3, specifically an ACC of $\sim 0.27-0.5\left(\operatorname{ref}^{6}\right)$.

372 Similarly, the SAM is a source of predictability and prediction skill of rainfall, 373 temperature and heat extremes over Australia ${ }^{89}, \underline{90}$. Although SAM predictability is 374 typically low beyond $\sim 2$ weeks, there is the potential to make seasonal 375 predictions ${ }^{91}$ because of its association with $\mathrm{ENSO}^{92}$ and the influence of the 376 stratosphere $\underline{\underline{81}, \underline{\underline{ }} \text {. }}$.

377 Consideration of these modes offers 'windows of opportunity' in S2S prediction, 378 where in certain situations there could be better predictability owing to active periods 379 of the MJO or certain large-scale atmospheric regimes, for example ${ }^{94}$.

\section{H2] Initial state}

382 Given that the land surface varies more slowly than the atmosphere, it also provides a 383 source of predictability for temperature and precipitation on S2S timescales, the 384 greatest contribution coming from soil moisture ${ }^{95}$. This predictability is most 385 pronounced during boreal spring and summer when synoptic systems have a smaller influence on soil moisture variability. The contribution of soil moisture anomalies to subseasonal predictability also varies regionally, with the largest contribution in areas 388 of strong land-atmosphere interactions ${ }^{96}$. As such, the land surface is initialized in most current operational subseasonal prediction systems and all research subseasonal 
systems (Supplementary Tables 1 and 2). In doing so, improved skill for S2S predictions of temperature and precipitation have been observed, although model errors impact the full realization of this skill $\underline{95,97, \underline{98}}$.

393 The coupling of the atmosphere to the ocean and sea ice is further thought to be 394 important for predictability at lead times longer than 2 weeks, and, accordingly, ocean-sea ice-atmosphere coupled models are routinely used in operational S2S initialized predictions. For Arctic sea ice, there is rising demand for reliable projections up to months ahead owing to increased human activities. Currently, the

398 best subseasonal models show skilful forecasts of more than 1.5 months ahead $\underline{99}$. Yet 399 many current operational forecast models lack skill even on timescales of a week $\underline{100}$. 400 Hence, there is more work to be done to improve the S2S forecast skill of Arctic sea 401 ice variables, although many systems are capable of predicting the sea ice extent at 402 seasonal timescales, at least in some regions and seasons $\underline{101}, \underline{102}, \underline{103}, \underline{104}$.

403 Sea ice conditions (such as the location of the sea ice edge) can have significant 404 feedback with the atmosphere and, thus, impact the forecast of the coupled system in 405 initialized predictions $\frac{105}{}$. For example, the largest mid-latitude forecast skill 406 improvements have occurred owing to improved Arctic predictions over eastern 407 Europe, northern Asia and North America relating to sea ice reductions and 408 anomalous anticyclonic circulation $\frac{106}{}$.

\section{0 [H2] The stratosphere}

411 The largest recognized influence of the stratosphere on the troposphere comes from 412 extreme states of the stratospheric polar vortex, particularly SSWs. SSWs are 413 followed by tropospheric circulation anomalies that can last up to 60 days and 414 resemble the negative phase of the $\mathrm{NAO}^{\frac{107}{108}}$. S2S forecasts initialized near the onset 
of an SSW thus show increased skill for mid-latitude to high-latitude surface

416 climate $\frac{109}{}$, and seasonal predictability of the NAO is dependent on the presence of

417 SSWs in ensemble predictions $\frac{110}{}$. Although SSWs are not as common in the southern

418 hemisphere, weakening and warming of the stratospheric polar vortex is predictable a

419 season in advance and, through connections with a negative SAM, can offer some

420 predictability of hot and dry extremes over Australia ${ }^{\underline{81}, \underline{93}}$.

421 The QBO can further influence the troposphere on S2S timescales. Specifically, phase

422 changes in the QBO modify the strength of the stratospheric polar vortex $\frac{111}{2}$, in turn

423 affecting the subtropical jet and storm tracks and, hence, surface climate $\frac{112,113}{\text {, and the }}$

424 strength of the $\mathrm{MJO}^{114, \underline{115}}$. For example, the phase of the QBO in the initial state

425 influences the prediction skill of the MJO, with higher skill during easterly QBO

426 boreal winters compared with westerly QBO winters and improved skill for lead

427 times of $1-10$ days $\frac{116}{}$. The prediction skill of the QBO itself is very high on the S2S

428 timescales, with an ACC of $0.85-1.0$ at a 1-month timescale ${ }^{93}$.

\section{[H1] S2I initialized predictions}

431 S2I initialized predictions are relatively mature compared with S2S and S2D, as

432 evidenced by the number of national operational meteorological services that

433 maintain state-of-the-art initialized S2I prediction systems $\stackrel{7,117}{ }$. Primary sources and

434 mechanisms of S2I predictability consist of slowly evolving boundary conditions of

435 SST, land surface conditions (moisture, snow cover), sea ice variations $\frac{118}{}$ and

436 stratospheric state. Additional predictability might be gained from the atmospheric

437 composition, not typically represented in S2I models. Each of these factors are now

438 discussed. 
441 The largest source of S2I predictability is associated with ENSO. ENSO provides skill

442 in predicting rainfall across the tropics $\frac{119}{}$ and surface climate across the globe given

443 their teleconnections $\frac{120}{}$. This predictability skill is primarily derived from subsurface

444 ocean processes $\frac{121}{2}$. Specifically, given that winds and SSTs in the deep tropical

445 Pacific are largely in equilibrium, and the subsurface temperature or thermocline

446 variations are in disequilibrium, capturing the latter in the initial state of ESMs offers

447 predictability $\frac{121}{}$.

448 However, ENSO events exhibit a large diversity in spatial patterns, with the location

449 of maximum SST anomalies ranging from the central Pacific to the far-eastern

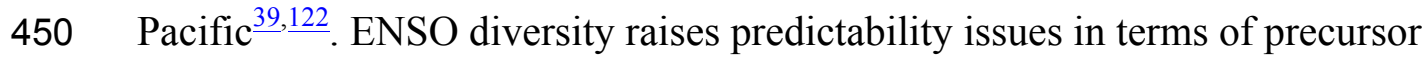

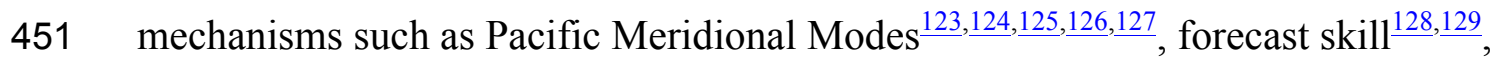

452 teleconnections $\frac{130}{}$, multi-year events $\frac{131}{2}$ and interpretation in the palaeo record $\frac{132}{-}$

453 many of which remain unresolved.

454 Overall, current state-of-the-art prediction systems are able to predict SSTs in the 455 eastern Pacific up to 6-9 months in advance with modest skill, especially for forecasts initialized in June and verified in the following boreal winter. Yet current prediction systems consistently struggle to predict through the boreal spring season, that is, the so-called spring prediction barrier. The rapid onset or initiation of canonical, eastern Pacific ENSO events also remains a challenge to predict, largely because onset often requires stochastic triggers such as westerly wind bursts $\underline{133,134}$. Indeed, inclusion of westerly wind bursts (or other triggers) as stochastic parameterizations has been found to improve model simulations of $\mathrm{ENSO}^{135}$ and forecast skill ${ }^{136}$. Prediction of different ENSO types appears to be limited to about 1 month $\frac{137}{}$ and, owing to the models' systematic tendency to produce more warming in the east, strong eastern Pacific 
events are generally better predicted (that is, exhibit better forecast skill) than central Pacific events ${ }^{7}$.

\section{[H2] Other modes of variability}

469 Tropical Atlantic SST anomalies are also predictable on S2I timescales. SST anomaly

470 variability in this region is broadly categorized into two spatial patterns. The first is

471 often referred to as the 'Atlantic Niño' and involves many of the feedback

472 mechanisms noted for $\mathrm{ENSO}^{138}$, but is shorter lived and weaker. In comparison with

473 ENSO, however, the Atlantic Niño is less studied and also less predictable $\frac{139,140}{\text {. The }}$

474 second pattern of variability is referred to as the Atlantic Meridional Mode ${ }^{87}$. It is

475 estimated that the Atlantic Meridional Mode is predictable one to two seasons in

476 advance, with the mechanisms for predictability largely stemming from near-surface

477 air-sea interactions (thermocline variability is of secondary importance). However,

478 even with some indications of successful predictions in certain circumstances

479 including interactions with the tropical Pacific ${ }^{138}$, as with all timescales of initialized

480 predictions, persistent regional systematic errors with current initialized Earth

481 prediction systems continue to be a factor in limiting the predictive abilities of

482 tropical Atlantic S2I variability $\underline{\underline{141}, \underline{142} .}$

483 Much like the Atlantic, Indian Ocean SST anomaly variability is weaker and may be

484 less predictable than the Pacific, but is important for regional teleconnections and 485 impacts. Indian Ocean SST variability has three distinct patterns of interest: the IOD,

486 which can be triggered by ENSO but can also emerge independently $\underline{58,143}$; a basin-

487 wide pattern that is an ENSO teleconnection ${ }^{144}$; and a meridional mode pattern that

488 depends on near-surface air-sea interactions similar to that in the Atlantic $\stackrel{145}{ }$. Earth

489 System prediction models typically struggle to predict the connection between ENSO 
and the IOD, the northward propagation of the meridional mode and the persistence of the IOD, except in large-amplitude cases $\frac{146}{}$. The IOD also can affect processes on the $\mathrm{S} 2 \mathrm{~S}$ timescale $\frac{147}{}$, including the MJO, and even the extratropics. There are also

493 other possible sources of S2I predictive skill involving the NAO ${ }^{148}$ and the Atlantic 494 Ocean state that appear to drive aspects of summer European rainfall $\stackrel{149}{ }$.

\section{H2] Land Surface Processes}

Slowly varying S2I soil moisture anomalies influence the prediction skill for

498 precipitation and temperature $\frac{150}{}$. Currently, the memory resulting from large soil

499 moisture anomalies in the initial conditions is believed to last $\sim 2-3$ months $\frac{151}{\text {, but }}$

500 there are case by case examples where predictability can be considerably longer under

501 conditions where soil moisture anomalies persist for more than one season,

502 particularly for surface temperature. Indeed, some seasonal temperature predictability

503 has been confirmed to arise from soil moisture, but the realization of skill is severely

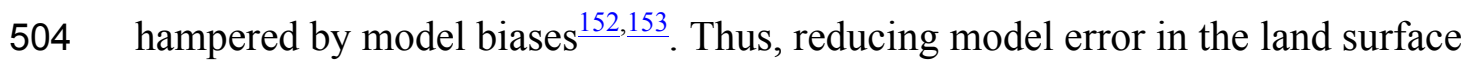

505 components could considerably improve forecast skill, as seen in a large sample of

506 initialized Earth System prediction experiments ${ }^{17}$.

\section{$508[\mathrm{H} 2]$ Stratosphere}

509 Improved surface prediction resulting from stratosphere-related processes has been

510 demonstrated on the seasonal timescale: having a higher vertical resolution in the

511 stratosphere in a GCM captures SSWs earlier compared with the standard model

512 configuration and has a positive influence on the simulations of European surface

513 climate $\frac{154}{2}$. Southern hemisphere SSWs also affect predictions of Australian

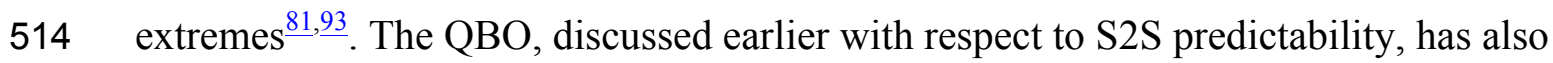


515 been shown to lead to enhanced predictability on seasonal timescales $\frac{155,156}{\text {, is }}$

516 predictable up to several years ahead $\frac{157}{2}$ and can also involve the $\mathrm{MJO}^{116}$.

517

518 [H2] Other possible sources of predictive skill

519 There are additional sources and mechanisms for S2I predictability that are not

520 particularly well modelled in S2I prediction. For example, slowly evolving

521 greenhouse gases such as carbon dioxide and methane are known to be a source of

522 forecast skill owing to their role as external forcing agents $\frac{158}{}$. However, an

523 approximate time history of carbon dioxide, methane and chlorofluorocarbons is

524 typically specified and not predicted, thus limiting the potential to capture S2I

525 variability or regional effects. Moreover, dust and aerosol concentrations are known

526 to affect human health, but these changes in atmospheric composition are usually not

527 included in prediction systems.

528

529 [H1] S2D initialized predictions

530 There is a high level of interest in, and expectations of, initialized Earth System

531 predictions on timescales beyond S2S and S2I. For example, even with their

532 limitations, there is evidence of skill in predicting surface temperature over and above

533 that of simple persistence (Fig. 6a,b), and also precipitation and sea level pressure

534 when using large multi-model ensembles, albeit with less skill $\frac{36}{}$. These skilful multi-

535 year predictions of precipitation over land indicate potential benefit to communities,

536 as demonstrated with summer drought indicators in major European agricultural

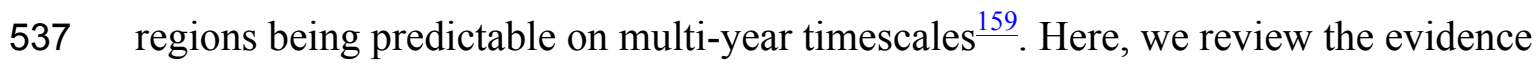


for processes and mechanisms acting on the S2D timescale that could contribute to the skill of initialized predictions $\underline{12, \underline{36}}$.

\section{[H2] Modes of decadal SST variability}

Processes and mechanisms have been identified that could provide skill for fundamental quantities such as SST in initialized predictions. Attention has been focused on $\mathrm{AMV} \stackrel{160}{ }$, but predictions of $\mathrm{PDV} \underline{160,161}$ — which are often described in terms of the Interdecadal Pacific Oscillation (IPO) $\frac{162}{2}$ over the Pacific basin and the Pacific Decadal Oscillation $\underline{163,164}$ over the north Pacific — are also of interest. Other modes of variability associated with decadal timescales include the Meridional Modes $\frac{165}{}$ and the North Pacific Gyre Oscillation $\frac{166}{}$.

Basin-wide warming and cooling patterns of SSTs and upper ocean heat content (averaged temperature for $0-400 \mathrm{~m}$ ) have also been shown to characterize decadal timescale variability in the Indian Ocean $\underline{167, \underline{168,}} \underline{169}$, as have decadal variations of the $\mathrm{IOD}^{56,170}$. Decadal variability in the Indian Ocean could influence warming events near the Australian west coast $\frac{171,172}{}$. Furthermore, a rapid rise in Indian Ocean subsurface heat content in the 2000s in observations and model simulations is associated with a redistribution of heat from the Pacific to the Indian Ocean and has been suggested to account for a large portion of the global ocean heat gain during that period $\stackrel{173,174}{ }$. IPO variability could thus be affecting Indian Ocean variability, transmitted through both the atmospheric and oceanic bridges $\frac{175}{}$. These lowfrequency connections have been implicated in modulating interannual variability associated with the IOD on decadal timescales $\underline{172,176}$.

One issue that remains to be resolved for S2D related to prediction skill is whether there are well-defined timescales of variability that are distinct from the background 
of climatic noise; that is, whether there are modes of large-scale variability that might display a statistically significant spectral peak in the decadal to multi-decadal range and that could be predicted. Such signals could offer the best prospect for long-term predictability, but on this timescale there is more of a broadband spectral peak. For example, CMIP5 control simulations showed patterns and multi-decadal timescales of variability in the Pacific associated with the IPO that resemble observations but with lower amplitude $\frac{177}{}$. Moreover, analysis of three generations of climate models (CMIP3, CMIP5 and CMIP6) shows progressive improvement of climate models' simulations of PDV $\stackrel{178}{ }$. However, there was no convincing evidence across these state-of-the-art coupled models for distinct oscillatory signals, other than on the interannual (years 3-7) ENSO timescales $\frac{179}{}$. These observations suggest, as noted previously, that low frequency variability on interdecadal timescales is characterized by broadband rather than oscillatory behaviour.

\section{[H2] Global temperatures}

The idealized 'rising staircase' (Fig. 6c) of global mean surface temperature (GMST) trends represents actual epochs of larger or smaller amplitude-positive GMST trends

(Fig. 6d) in a world with steadily increasing positive radiative forcing from increasing greenhouse gases $\frac{180}{}$. This increase in radiative forcing means that the entire Earth System warms continuously, but the manifestation of that warming at the Earth's surface on decadal timescales depends on how heat is redistributed in the climate system: if more heat remains near the ocean surface, the GMST rate of warming will be larger, but if more heat is distributed into the deeper ocean, then the GMST trend will be reduced $\stackrel{44,181}{ }$. 
It is recognized that the slowdown in the rate of GMST warming in the early 2000s was likely a combination of internal variability from the negative phase of the

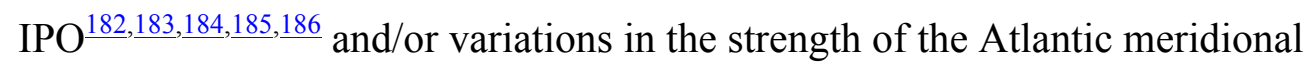

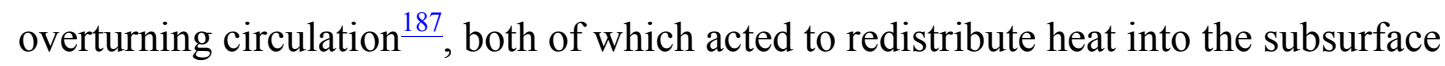
ocean. However, there is disagreement on whether the heat is primarily stored in the tropics $\frac{174}{}$ or at high latitudes $\frac{181}{}$. External forcing from a collection of moderate-sized volcanic eruptions $\frac{188}{}$ and from anthropogenic aerosols $\frac{189}{m}$ might have also played a role in the slowdown, although their contribution is not entirely settled $\frac{190}{}$. Initialized predictions have been shown to successfully predict the onset of the GMST warming slowdown, linked to increased ocean heat uptake in the tropical Pacific and

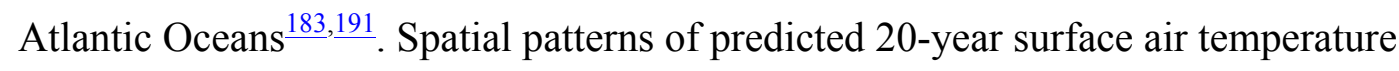
trends have been shown to depend on the initial state of the Pacific Ocean $\frac{192}{2}$, with initialized model predictions exhibiting a large spread in projected multi-decadal global warming unless the initial state of the Pacific Ocean is known and well represented in the model. Apart from its connection to the recent global warming slowdown, the negative phase of the IPO has also been linked to regional climate changes at higher latitudes, including the rate of Arctic sea ice decrease in the early 2000 s (ref. ${ }^{193}$ ) and Antarctic sea ice expansion during that same period ${ }^{194,195}$. Statistical methods ${ }^{47}$ and initialized predictions ${ }^{\underline{70}, 196}$ foretold a transition of the IPO in the tropical Pacific from negative to positive in the 2014-2015 time frame, with a resumption of more rapid rates of global warming thereafter. There is observational evidence that this IPO transition also contributed to initiating rapid Antarctic sea ice retreat $\frac{197}{}$.

There is a chronic shortage of observed data in the ocean to document heat redistribution. In models, this redistribution has been shown to involve the subtropical 
cells in the Pacific, Antarctic Bottom Water formation and the AMOC in the Atlantic ${ }^{2,44}$, as well as changes in the zonal slope of the equatorial thermocline $\mathrm{e}^{182,198}$ associated with changes in tropical winds. However, deciphering decadal timescale variability in the observed climate system, and interpreting such variability in the context of initialized predictions, is complicated by the presence of external forcings (such as anthropogenic and volcanic aerosols and solar forcing) that can produce decadal variability in the Pacific $\frac{189}{}$ or Atlantic $\underline{199,200}$ with similar patterns to presumptive internally generated decadal climate variability $\underline{180,201,202}$.

\section{[H2] Interactions between ocean basins}

Interactions between various ocean basins are one of the most compelling science questions that have arisen regarding the origins and nature of decadal climate variability, with implications for initialized prediction skill $\underline{160,203,204}$. For instance, if a skilful prediction of climate in one basin is achieved, then skilful simulations in the other basins could follow (if the models capture these connections realistically), thus improving the skill of initialized S2D predictions.

SST variability in one ocean basin can affect the others through the tropical largescale east-west atmospheric Walker Circulation, although the direction of those influences differs $\stackrel{204,205}{ }$. For example, model simulations have indicated that decadal timescale variability in the Atlantic could produce decadal timescale variability in the Pacific ${ }^{61,206,207,208}$. PDV can also affect the Atlantic $\frac{194,209,210}{2}$ and control a large fraction of decadal variability in the Indian Ocean $\underline{58,172, \underline{211}, \underline{212,213}}$. Similarly, the Indian Ocean could influence decadal variability in the Pacific $\stackrel{168,203,214}{2}$. There also could be staggered responses based on decadal timescales, with the tropical Pacific driving the tropical Atlantic on interannual timescales, with the Atlantic then affecting the Indian 
637 Ocean and, subsequently, the Pacific on decadal timescales $\underline{215,216}$. It has further been 638 postulated that the tropical Atlantic and Pacific Oceans are mutually interactive on

639 decadal timescales, with each alternately affecting the other ${ }^{205}$, and that the tropical

640 Pacific could be driving the extratropical Pacific $\stackrel{217}{ }$.

641 External forcing, particularly from time-evolving anthropogenic aerosols, is another

642 factor that could produce decadal climate variability and inter-basin

643 connections $\underline{189,199, \underline{218}}$. Such fundamental interactions all currently fall under the

644 heading of a compelling research frontier that, with increased understanding, will

645 certainly advance the science of initialized prediction.

646

647

[H1] Summary and future perspectives

648 Numerical models initialized with observations for specific time periods and

649 integrated forward in time provide a continuum of predictions on different timescales

650 from S2S to S2I and S2D. Results so far demonstrate initialized prediction skill for

651 variables such as surface temperature and key modes of atmospheric and ocean

652 variability. Such skill has been demonstrated, for example, for the MJO on S2S

653 timescales, for ENSO on S2I timescales and for surface temperatures in most ocean

654 regions on S2D timescales. Yet, despite progress in predictions and processes, there

655 are still many challenges and priorities for future research.

656

657 [H2] Model error

658 Almost every science-related aspect of subseasonal to decadal climate variability has

659 considerable uncertainty associated with it. Therefore, apart from fundamental

660 scientific understanding, perhaps the key obstacle to progress is model error,

661 particularly with regards to biases and drifts. Progress thus requires model 
improvement, developments of which are difficult but not impossible. In recent years, for instance, model development work has been undertaken in the coupled space, improving simulation of atmosphere-ocean phenomena that give rise to predictability (such as the MJO and ENSO), and therefore minimizing the exacerbation of drift when developed in isolation. Model improvements depend critically on our understanding of processes and mechanisms and how they work in the climate system, as it is difficult to model what is not understood. Therefore, enhanced observational and analysis projects must continue to provide the knowledge base from which to make improvements to the model simulations.

Model error remains a significant obstacle against which future progress will be measured, with profound implications for possible applications to stakeholder communities. Such applications could include energy supply (wind, solar) and demand $\frac{219}{}$, agriculture (drought, freezing), transport $\frac{220}{2}$ and numerous others spanning a range of timescales. Notably, S2S prediction could inform preparedness for specific large-scale extreme events weeks ahead ${ }^{5}$, and S2I and S2D initialized predictions are beginning to inform planning at ranges between the seasonal and multi-decadal climate change timescales $\frac{221}{\text {. }}$.

In addition to coupled model development, increased model resolution has also shown the ability to improve model bias and the signal to noise ratio. Consequently, the benefit of increased model resolution is one of the research frontiers of initialized prediction. However, such increased resolution must also be accompanied by comparable increases in the quality of the physical parameterizations such as cloud feedback and cloud-aerosol interactions. Although we are still very likely decades away from having global coupled models (and suitable machines) capable of explicitly resolving processes that would improve model bias (such as atmospheric 
convection and ocean eddies), approaches have been developed to reduce computational cost and bias. These approaches include flux correction techniques $\frac{222}{\text {, }}$ parameter estimation $\frac{223}{}$, reducing the precision of some variables $\frac{224}{2}$ and stochastic modelling 225 . Additionally, machine learning techniques are providing indications of improving predictive skill. For example, a deep-learning approach using a statistical forecast model has been shown to produce skilful ENSO forecasts for lead times of up to 1.5 years ${ }^{226}$. Utilization of GPU-based computer architectures could become useful and open the way to better parametrizations that depend on intensive calculations that can be addressed with GPU architectures.

\section{[H2] Initialization}

Integrating the vast amount of observed information into an ESM is central to the S2D prediction. Traditionally, the most advanced data assimilation techniques were implemented in the atmospheric component. In the last decade, however, there has been growing interest in how to fully utilize relevant satellite and in situ observations to improve S2S and S2I predictions. Coupled ocean-atmosphere data assimilation $\underline{28,227, \underline{228}}$ shows promising evidence that coupling can reduce 'initialization shock' and improve forecast performance on timescales of weeks to decades $\frac{229}{}$. The advancement has led to coupled reanalysis products for both the ocean and the atmosphere (CFSR by $\mathrm{NCEP}^{230}$ and CERA by $\mathrm{ECMWF}^{231}$ ) and is expected to substantially improve S2S and S2I predictions.

Compared with S2S and S2I predictions, there remain critical obstacles to how to initialize decadal predictions. First, there is a lack of observations. S2D models need to be initialized in the 1960 s and 1970 s in order to calibrate the decadal prediction systems and achieve the potential to capture the evolution of low-frequency modes of 
713 temperature and salinity prior to the advent of Argo floats remains a large problem.

714 Currently, most modelling centres performing decadal predictions do not carry out

715 their own assimilation exercise; rather, they simply nudge some reanalysis products in

716 the ocean and atmosphere (Supplementary Table 3). How to best initialize the ocean

717 without reliable subsurface observations, and how the inhomogeneity of the

718 observations can impact model performance, have not been carefully investigated.

719 Building ensembles is another key obstacle to decadal prediction, as common practice

720 in the community is to use an ensemble of ten members following the CMIP5 and

721 CMIP6 experimental designs. A large ensemble consisting of 40 members can

722 provide better opportunities for skilful predictions of low-frequency climate

723 variability over land in selected regions ${ }^{20}$. However, compared with the atmosphere,

724 there is very limited understanding of the mechanisms and uncertainty associated with

725 the low-frequency internal variability in the ocean owing to the lack of long-term

726 observations of the subsurface ocean, and thus lack of guidance as to how to build the

727 ensemble. Machine learning methods could help address this problem, although the

728 lack of long-term subsurface ocean observations will always be a factor for the S2D

729 timescale. Finally, a major constraint is computational capability, both for

730 initialization and for running adequate numbers of ensembles to improve skill ${ }^{33}$. The

731 future of initialized prediction will depend on computational resources balanced with

732 factors involving increased resolution, machine learning, use of new high-

733 performance computing architectures and developments in exascale computing. 
There are considerable future challenges for understanding internal variability in the context of initialized prediction. These include the need to have a better understanding and better estimates of predictability. Additionally, research is needed regarding why models appear to underestimate the magnitude of predictable signals compared with unpredictable variability, and this involves the response to external forcing as well ${ }^{232}$. One issue that remains to be resolved for S2D initialized predictions is whether there are well-defined processes and mechanisms that, if initialized properly, could provide predictable signals distinct from the background of climatic noise. Signals from PDV and AMV offer the best prospect for long-term predictability. Strong low-frequency variability in palaeoclimate 'proxy' records, which is not captured by most climate models, suggests either that models do indeed underestimate low-frequency modes of variability or that proxy observations contain significant residual non-climatic sources

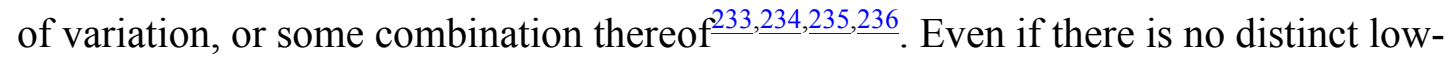
frequency (oscillating) phenomenon, predictability on decadal timescales could also come from memory and slowly varying components of the Earth System, such as the slow propagation of oceanic planetary waves $\frac{237,238}{2}$ or natural volcanic forcing ${ }^{47}$, and initialization could be expected to contribute to skill in such cases.

\section{[H2] Expanding predicted variables}

There is interest in, and corresponding applications for, expanding beyond the prediction of surface temperature, precipitation and SST. Predictions of the frequency of extreme events such as tropical storms and hurricanes have great potential as climate services. There have been efforts at predicting soil moisture with implications for drought prediction $\frac{239}{3}$ and ecosystem respiration $\frac{240}{2}$, as well as snowpack with 
ramifications for water resources $\underline{241,242}$ and marine heatwaves $\underline{243}$. There is also a great

761 societal need for prediction of sea ice on S2I and S2D timescales. Some S2I models

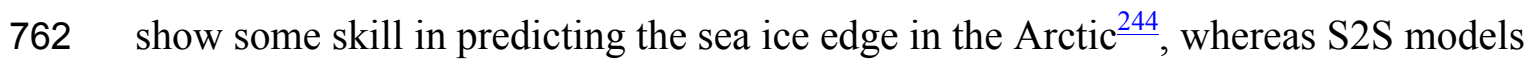

763 show a very wide range of skill in predicting the sea ice edge in the Arctic, with the

764 most skilful models producing useful forecasts up to 45 days ${ }^{99}$. Although the potential

765 for skilful initialized predictions of Arctic sea ice on S2S timescales has improved in

766 the last decade, there is still a lot more to be explored and improved ${ }^{101}$. We still need

767 to understand what are the key processes driving subseasonal variations of sea ice and

768 to improve the representation of these processes in the S2S models. Improved coupled

769 data assimilation of the ocean, sea ice and atmospheric coupled system can help

770 improve initial conditions for coupled forecasts and, concomitantly, the forecast skill

771 of features that are sensitive to the initial state $\underline{\underline{14,245,246}}$.

772 Other important aspects of the cryosphere relevant to initialized prediction on S2D

773 timescales are ice sheets. As new interactive ice sheet simulations and spin-up

774 procedures come increasingly online $\frac{247}{}$, this will provide an additional opportunity for 775 initialized S2D predictions.

776 Air pollution and air quality are other very society-relevant applications that have

777 been largely unexplored owing to the lack of inclusion of interactive tropospheric

778 chemistry in most S2S, S2I and S2D models. However, new comprehensive ESMs,

779 such as the Community Earth System Model with the Whole Atmosphere Community

780 Climate Model as its atmospheric component (CESM2-WACCM ${ }^{248}$ ), will be able to

781 explore this research area.

782 In the broader Earth System, there is growing interest in predicting the biosphere and

783 biogeochemical state variables and fluxes that could inform management decisions.

784 Skilful initialized predictions of SST on S2S timescales can engender predictability of 
785 fish yields in the California Current System ${ }^{249}$ and other large marine ecosystems $\stackrel{250}{ }$.

786 S2S initialized predictions of heat stress and coral bleaching risk have also

787 demonstrated considerable skill and have provided critical advanced warning for coral

788 reef scientists, managers and stakeholders $\frac{251}{5}$. SST anomalies in the western tropical

789 Pacific and northern subtropics, often associated with ENSO events, appear to be

790 skilful precursors for variations in temperature and related biological productivity

791 along the US West Coast on S2I timescales $\frac{252}{2}$.

792 Emerging literature on S2D predictions of biogeochemistry in the terrestrial biosphere

793 and ocean suggests that slowly evolving state variables could enable prediction of

794 biogeochemically relevant quantities with greater skill than physical state variables

795 such as temperature and precipitation. For example, predictions of marine net primary

796 production by photosynthesizing phytoplankton (including algae, eukaryotes and

797 cyanobacteria) might foretell future potential fisheries catches, predict harmful algal

798 blooms $\underline{253}$ and aid with fisheries management strategies $\underline{253,254,255,256}$, as would skilful

799 predictions of ocean oxygen content or acidity 5 , 258 . Reliable forecasts of the

800 changing global carbon budget, including the rate of ocean carbon

801 absorption $\underline{216,259,260,261}$ or the rate of terrestrial biosphere-atmosphere net ecosystem

802 exchange $\frac{240,259}{}$, could help to generate forecasts of atmospheric $\mathrm{CO}_{2}$ growth rate and

803 contribute to $\mathrm{CO}_{2}$ emission management strategies. Additionally, there has been

804 demonstrated S2I skill at predicting net primary production related to fire risk $\frac{262}{}$.

805 Recently reported skilful predictions of chlorophyll concentrations over the global

806 oceans at seasonal to multi-annual timescales have been related to the successful

807 simulation of the chlorophyll response to ENSO, and to the winter re-emergence of

808 subsurface nutrient anomalies in the extratropics ${ }^{255}$. Chlorophyll not only responds to

809 ENSO, but can also constitute a potentially useful ENSO precursor $\stackrel{263}{ }$. 
810

811 directly observed at the spatial and temporal scales needed for forecast verification,

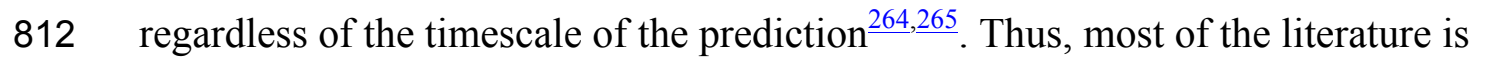

813 focused on the potential to make predictions of these quantities, rather than on skill as

814 measured by historical observations $\underline{254,256,259,260}$, with exceptions $\underline{216,257,258}$. On the

815 global scale, verification is limited to variables measured or derived from satellite

816 observations, such as ocean chlorophyll $\frac{255}{2}$, marine primary productivity $\frac{20}{}$ or

817 interpolated estimates of the surface ocean partial pressure of $\mathrm{CO}_{2}\left(\right.$ ref. $\left.\frac{261}{}\right)$.

818 Nevertheless, there is promising potential to make ocean biogeochemical initialized

819 predictions across multiple timescales.

820 For S2S, S2I and S2D initialized predictions to be useful, they must be shown to be 821 not only skilful but reliable $\mathrm{e}^{266}$, and this is a considerable challenge that the community

822 is only starting to attempt to address $\frac{5,21}{}$. The ultimate challenge in this emerging area

823 of research, and one that is igniting excitement and interest in the scientific

824 community, is to provide predictions with maximum skill that take into account all

825 relevant processes across subseasonal to decadal timescales $\underline{267,268,269}$. Towards that

826 end, initialized prediction is already put to task and being applied in various sectors

827 even as improvements in understanding and prediction capability are being improved,

828 thus driving rapid advances in this burgeoning field.

\section{$831 \quad$ References}

832 1. Meehl, G. A. et al. Decadal prediction. Bull. Am. Meteorol. Soc. 90, 1467-

$8331486(2009)$. 
2. Meehl, G. A., Hu, A., Arblaster, J. M., Fasullo, J.

\& Trenberth, K. E. Externally forced and internally generated decadal climate variability associated with the Interdecadal Pacific Oscillation. J. Clim. 26, 7298-7310 (2013).

3. Hawkins, E. \& Sutton, R. (2009). The potential to narrow uncertainty in regional climate predictions. Bull. Am. Meteorol. Soc. 90, 1095-1108 (2009).

4. Lehner, F. et al. Partitioning climate projection uncertainty with multiple large ensembles and CMIP5/6. Earth Syst. Dynam. 11, 491-508 (2020).

5. Vitart, F. \& Robertson, A. W. The Sub-Seasonal to Seasonal Prediction Project (S2S) and the prediction of extreme events. npj Clim. Atmos. Sci. 1, 3

6. Pegion, K. et al. The Subseasonal Experiment (SubX). Bull. Amer. Meteorol. Soc. 100, 2043-2060 (2019).

7. Kirtman, B. P. et al. The North American multimodel ensemble: phase-1 seasonal to interannual prediction; phase-2 toward developing intraseasonal prediction. Bull. Amer. Meteorol. Soc. https://doi.org/10.1175/BAMS-D- 1200050.1 (2014).

8. Boer, G. J. et al. The Decadal Climate Prediction Project (DCPP) contribution to CMIP6. Geosci. Model Dev. 9, 3751-3777 (2016).

9. Palmer, T. N., Doblas-Reyes, F. J., Weisheimer, A. \& Rodwell, J. J. Toward seamless prediction: calibration of climate change projections using seasonal forecasts. Bull. Amer. Meteorol. Soc. 89, 459-470 (2008). 
10. Branstator, G. \& Teng, H. Potential impact of initialization on decadal predictions as assessed for CMIP5 models. Geophy. Res. Lett. https://doi.org/ 10.1029/2012GL051974 (2012).

11. Barnett, T. et al. On the prediction of the El Niño of 1986-1987. Science 241, 192-196 (1988).

12. Kushnir, Y. et al. Towards operational predictions of the near-term climate. Nat. Clim. Chang. https:// doi.org/10.1038/s41558-018-0359-7 (2019).

13. Lean, P. et al. Continuous data assimilation for global numerical weather prediction. Q J R Meteorol. Soc. https://doi.org/10.1002/qj.3917 (2020).

14. Sandery, P. A., O’Kane, T. J., Kitsios, V. \& Sakov, P. Climate model state estimation using variants of EnKF coupled data assimilation. Mon. Weather Rev. 148, 2411-2431 (2020).

15. Johnson, C., Hoskins, B. J. \& Nichols, N. K.

A singular vector perspective of 4D-Var: filtering and interpolation. $Q J R$ Meteorol. Soc. 131, 1-19 (2005).

16. Magnusson, L., Nycander, J. \& Kallen, E. Flow-dependent versus flowindependent initial perturbations for ensemble prediction. Tellus A 61, 194209 (2009).

17. Infanti, J. M. \& Kirtman, B. P. Prediction and predictability of land and atmosphere initialized CCSM4 climate forecasts over North America. $J$. Geophys. Res. Atmos. 121, 12,690-12,701 (2016b).

18. Trenary, L., DelSole, T., Tippett, M. K. \& Pegion, K. A new method for determining the optimal lagged ensemble. J. Adv. Model Earth Syst. 9, 291306 (2017). 
19. Kirtman, B. P. \& Min, D. Multi-model ensemble ENSO prediction with CCSM and CFS. Mon. Weather Rev. https://doi.org/10.1175/2009MWR2672.1 (2009).

20. Yeager, S. G. et al. Predicting near-term changes in the earth system: a large ensemble of initialized decadal prediction simulations using the community earth system model. Bull. Am. Meteorol. Soc. 99, 1867-1886 (2018).

21. Smith, D. M. et al. Real-time multi-model decadal climate predictions. Clim. Dyn. 41, 2875-2888 (2013a).

22. MacLachlan, C. et al. Global Seasonal Forecast System version 5 (GloSea5): a high resolution seasonal forecast system. $Q J R$ Meteorol Soc. https://doi.org/10.1002/qj.2396 (2014).

23. Muñoz-Sabater et al. Assimilation of SMOS brightness temperatures in the ECMWF integrated forecasting system. QJ R Meteorol Soc. https:// doi.org/10.1002/qj.3577 (2019).

24. Drewitt, G., Berg, A. A., Merryfield, W. J. \& Lee, W.-S. Effect of realistic soil moisture initialization on the Canadian CanCM3 seasonal forecast model. Atmos. Ocean 50, 466-474 (2012).

25. Polkova, I., Köhl, A. \& Stammer Climate-mode initialization for decadal climate predictions. Clim. Dyn. 53, 7097-7111 (2019).

26. Smith, D. M., Eade, R. \& Pohlmann, H. A comparison of full-field and anomaly initialization for seasonal to decadal climate prediction. Clim. Dyn. $41,3325-3338(2013)$.

27. Volpi, D., Guemas, V. \& Doblas-Reyes, F. J. Comparison of full field and anomaly initialisation for decadal climate prediction: towards an optimal 
consistency between the ocean and sea-ice anomaly initialisation state. Clim. Dyn. 49, 1181-1195 (2017).

28. Penny, S. G., et al. Coupled data assimilation for integrated earth system analysis and prediction: goals, challenges and recommendations. Technical report (World Meteorological Organisation, 2017).

29. Williams, K. D. et al. The Met Office Global Coupled Model 2.0 (GC2) configuration. Geosci. Model Dev. 8, 1509-1524 (2015).

30. Becker, E. \& Van Den Dool, H. Probabilistic seasonal forecasts in the North American multimodel ensemble: a baseline skill assessment. J. Clim. 29, 3015-3026 (2016).

31. Kadow, C. et al. Decadal climate predictions improved by ocean ensemble dispersion filtering. J. Adv. Model. Earth Syst. 9.2, 1138-1149 (2017).

32. Dobrynin, M. et al. Improved teleconnection-based dynamical seasonal predictions of boreal winter. Geophys. Res. Lett. 45, 3605-3614 (2018).

33. Smith, D. M. et al. North Atlantic climate far more predictable than models imply. Nature 583, 796-800 (2020).

34. Richter, J. H. et al. Subseasonal prediction with and without a wellrepresented stratosphere in CESM1. Weather and Forecasting, https://journals.ametsoc. org/view/journals/wefo/aop/WAF-D-20-0029.1/ WAF-D-20-0029.1.xml (2020).

35. Scaife, A. A. et al. Skillful long-range prediction of European and North American winters. Geophys. Res. Lett. 41, 2514-2519 (2014). Atmos. Sci. 2, 13 (2019). 
37. Athanasiadis, P. J. et al. Decadal predictability of North Atlantic blocking and the NAO. NPJ Clim. Atmos. Sci. 3, 20 (2020).

38. Nie, Y. et al. Stratospheric initial conditions provide seasonal predictability of the North Atlantic and Arctic oscillations. Env. Res. Lett. 14, 3 (2019)

39. Capotondi, A. et al. Understanding ENSO diversity. Bull. Am. Meteorol. Soc. 96, 921-938 (2015).

40. Cobb, K. M. et al. Highly variable El Niño-Southern Oscillation throughout the Holocene. Science 339, 67-70 (2013).

41. Capotondi, A. \& Sardeshmukh, P. D. Is El Niño really changing? Geophys. Res. Lett. https://doi.org/ 10.1002/2017GL074515 (2017).

42. Grothe, P. R. et al. Enhanced El Niño-Southern Oscillation variability in recent decades. Geophys. Res. Lett. https://doi.org/10.1029/2019GL083906 (2019).

43. Deser, C., Phillips, A. S. \& Alexander, M. A. Twentieth century tropical sea surface temperature trends revisited. Geophys. Res. Lett. 37, L10701 (2010). based evidence of deep ocean heat uptake during surface temperature hiatus periods. Nat. Clim. Change 1, 360-364 (2011). change. Eos 87, 233-241 (2006). internal variability and the AMO. ("Frontier" article). Geophys. Res. Lett. 41, 3211-3219 (2014). 
47. Mann, M. E. et al. Predictability of the recent slowdown and subsequent recovery of large-scale surface warming using statistical methods. Geophys. Res. Lett. 43, 3459-3467 (2016).

48. Steinman, B. A., Frankcombe, L. M., Mann, M. E., Miller, S. K. \& England, M. H. Response to comment on "Atlantic and Pacific multidecadal oscillations and Northern Hemisphere temperatures". Science 350, 1326 (2015).

49. Roemmich, D. \& Gilson, J. The 2004-2008 mean and annual cycle of temperature, salinity, and steric height in the global ocean from the Argo Program. Prog. Oceanogr. 82, 81-100 (2009).

50. Roemmich, D. et al. On the future of Argo: a global, full-depth, multidisciplinary array. Front. Mar. Sci. https://doi.org/10.3389/fmars.2019.00439 (2019).

51. Thompson, D. M., Cole, J. E., Shen, G. T., Tudhope, A. W. \& Meehl, G. A. Early twentieth-century warming linked to tropical Pacific wind strength. Nat. Geosci. 8, 117-121 (2015).

52. Cook, E. R. et al. Megadroughts in North America: placing IPCC projections of hydroclimatic change in a long-term palaeoclimate context. J. Quat. Sci. 25, 48-61 (2010).

53. Emile-Geay, J., Cobb, K. M., Mann, M. E. \& Wittenberg, A. T. Estimating central equatorial Pacific SST variability over the past millennium. Part II: reconstructions and implications. J. Clim. 26, 2329-2352 (2013).

54. Linsley, B. K., Wu, H. C., Dassié, E. P. \& Schrag, D. P. Decadal changes in South Pacific sea surface temperatures and the relationship to the Pacific decadal oscillation and upper ocean heat content. Geophys. Res. Lett. 42, 2358-2366 (2015). 
55. Buckley, B. M. et al. Interdecadal Pacific Oscillation reconstructed from transPacific tree rings: 1350-2004 CE. Clim. Dyn. 53, 3181-3196 (2019).

56. Abram, N. J. et al. Palaeoclimate perspectives on the Indian Ocean dipole. Quat. Sci. Rev. https://doi.org/ 10.1016/j.quascirev.2020.106302 (2020). 57. Sanchez, S. C., Charles, C. D., Carriquiry, J. D. \& Villaescusa, J. A. Two centuries of coherent decadal climate variability across the Pacific North American region. Geophys. Res. Lett. 43, 9208-9216 (2016).

58. Abram, N. J. et al. Coupling of Indo-Pacific climate variability over the last millennium. Nature 579, 385-392 (2020).

59. Konecky, B., Dee, S. G. \& Noone, D. WaxPSM: a forward model of leaf wax hydrogen isotope ratios to bridge proxy and model estimates of past climate. $J$. Geophys. Res. Biogeosci. https://doi.org/10.1029/ 2018JG004708 (2019).

60. Neukom, R. et al. Consistent multi-decadal variability in global temperature reconstructions and simulations over the common era. Nat. Geosci. 12, 643 (2019). 61. McGregor, H. V. et al. Robust global ocean cooling trend for the pre-industrial common era. Nat. Geosci. 8, 671-677 (2015).

62. Tierney, J. E. et al. Tropical sea surface temperatures for the past four centuries reconstructed from coral archives. Paleoceanography 30, 226-252 (2015).

63. Goosse, H. et al. Reconstructing surface temperature changes over the past 600 years using climate model simulations with data assimilation. J. Geophys. Res. 115, D09108 (2010).

64. Hakim, G. J. et al. The last millennium climate reanalysis project: framework and first results. J. Geophys. Res. Atmos. 121, 6745-6764 (2016). 
1000

1001

1002

1003

1004

1005

1006

1007

1008

1009

1010

1011

1012

1013

1014

1015

1016

1017

1018

1019

1020

1021

1022

1023

1024

65. Steiger, N. J., Jason, E. S., Cook, E. R. \& Cook, B. I. A reconstruction of global hydroclimate and dynamical variables over the common era. Sci. Data 5, 180086 (2018).

66. Evans, M. N., Tolwinski-Ward, S. E., Thompson, D. M. \& Anchukaitis, K. J. Applications of proxy system modeling in high resolution paleoclimatology. Quat. Sci. Rev. 76, 16-28 (2013).

67. Dee, S. et al. PRYSM: an open-source framework for PRoxY system modeling, with applications to oxygen-isotope systems. J. Adv. Model. Earth Syst. 7, 1220-1247 (2015).

68. Becker, E., Dool, den, H. V. \& Zhang, Q. Predictability and forecast skill in NMME. J. Clim. 27, 5891-5906 (2014).

69. Doblas-Reyes, F. J. et al. Initialized near-term regional climate change prediction. Nat. Commun. 4, 1715 (2013).

70. Meehl, G. A., Hu, A. \& Teng, H. Initialized decadal prediction for transition to positive phase of the Interdecadal Pacific Oscillation. Nat. Commun. https://doi.org/10.1038/NCOMMS11718 (2016).

71. Kharin, V. V., Boer, G. J., Merryfield, W. J., Scinocca, J. F. \& Lee, W.-S.

Statistical adjustment of decadal predictions in a changing climate. Geophys. Res. Lett. 39, L19705 (2012).

\section{Scaife, A. A. \& Smith, D. A signal-to-noise paradox} in climate science. npj Clim. Atmos. Sci. 1, 28 (2018).

73. Sévellec, F. \& Drijfhout, S. S. The signal-to-noise paradox for interannual surface atmospheric temperature predictions. Geophys. Res. Lett. 46, 9031-9041 (2019). 74. Zhang, W. \& Kirtman,, B. Estimates of decadal climate predictability from an interactive ensemble model. Geophys. Res. Letts. 46, 3387-3397 (2019). 
1025

1026

1027

1028

1029

1030

1031

1032

1033

1034

1035

1036

1037

1038

1039

1040

1041

1042

1043

1044

1045

1046

1047

1048

75. Weisheimer, A. et al. How confident are predictability estimates of the winter North Atlantic oscillation? Quart. J. R. Meteorol. Soc. https://doi.org/10.1002/ qj.3446 (2019).

76. Barnston, A. G., Tippett, M. K., L’Heureux, M. L., Li, S. \& DeWitt, D. G. Skill of real-time seasonal ENSO model predictions during 2002-11: is our capability increasing? Bull. Am. Meteorol. Soc. 93, 631-651 (2012).

77. Robertson, A. W. \& Vitart, F. (eds) Sub-seasonal to Seasonal Prediction (Elsevier, 2018).

78. Kim, H., Vitart, F. \& Waliser, D. E. Prediction of the Madden-Julian Oscillation: a review. J. Clim. 31, 9425-9443 (2018).

79. Stan, C. et al. Review of tropical-extratropical teleconnections on intraseasonal time scales. Rev. Geophys. 55, 902-937 (2017).

80. Kim, H., Richter, J. H. \& Martin, Z. Insignificant QBO-MJO prediction skill relationship in the SubX and S2S subseasonal reforecasts. J. Geophys. Res. Atmos. https://doi.org/10.1029/2019JD031416 (2019).

81. Lim, E.-P., Hendon, H. H. \& Thompson, D. W. J. Seasonal evolution of stratosphere-troposphere coupling in the southern hemisphere and implications for the predictability of surface climate. J. Geophys. Res. Atmos. 123, 1-15 (2018). 82. Zheng, C., Chang, E. K. M., Kim, H., Zhang, M. \& Wang, W. Subseasonal to seasonal prediction of wintertime northern hemisphere extratropical cyclone activity by S2S and NMME models. J. Geophys. Res. Atmos. https://doi.org/10.1029/2019JD031252 (2019).

83. DeFlorio, M. J. et al. Global evaluation of atmospheric river subseasonal prediction skill. Clim. Dyn. 52, 3039-3060 (2019). 
84. Baggett, C. et al. Skillful subseasonal forecasts of weekly tornado and hail activity using the Madden-Julian Oscillation. $J$. Geophys. Res. Atmos. 123, 12,661-12,675 (2018).

85. Broennimann, S. Impact of El Niño-Southern Oscillation on European climate. Rev. Geophys. 45, RG3003 (2007).

86. Ambaum, P. \& Hoskins, B. J. The NAO troposphere- stratosphere connection. J. Clim. 15, 1969-1978 (2002).

87. Kushnir, Y., Robinson, W. A., Chang, P. \& Robertson, A. W. The physical basis for predicting Atlantic sector seasonal-to-interannual climate variability. J. Clim. 19, 5949-5970 (2006).

88. Riddle, E. E., Butler, A. H., Furtado, J. C., Cohen, J. L. \& Kumar, A. CFSv2 ensemble prediction of the wintertime Arctic oscillation. Clim. Dyn. 41, 1099$1116(2013)$.

89. Hendon, H. H., Thompson, D. W. J. \& Wheeler, M. C. Australian rainfall and surface temperature variations associated with the southern hemisphere annular mode. J. Clim. 20, 2452-2467 (2007).

90. Marshall, A. G. et al. Intra-seasonal drivers of extreme heat over Australia in observations and POAMA-2. Clim. Dyn. 43, 1915-1937 (2014).

91. Seviour, W. J. M. et al. Skillful seasonal prediction of the southern annular mode and Antarctic ozone. J. Clim. 27, 7462-7474 (2014).

92. Lim, E.-P., Hendon, H. H. \& Rashid, H. A. Seasonal predictability of the southern annular mode due to its association with ENSO. J. Clim. 26, 80378054 (2013). 
93. Lim, E. et al. Australian hot and dry extremes induced by weakenings of the stratospheric polar vortex. Nat. Geosci. 12, 896-901 (2019).

94. Mariotti, A. et al. Windows of opportunity for skillful forecasts subseasonal to seasonal and beyond. Bull. Am. Meteorol. Soc. https://doi.org/10.1175/ BAMS-D-18-0326.1 (2020).

95. Dirmeyer, P. A., Halder, S. \& Bombardi, R. On the harvest of predictability from land states in a global forecast model. J. Geophys. Res. Atmos. 123, $13111-13127(2018)$.

96. Koster, R. D. et al. Regions of strong coupling between soil moisture and precipitation. Science 305, 1138-1140 (2004).

97. Koster, R. D. et al. The second phase of the global land-atmosphere coupling experiment: soil moisture contributions to subseasonal forecast skill. $J$. Hydrometeor. 12, 805-822 (2011).

98. Seo, E. et al. Impact of soil moisture initialization on boreal summer subseasonal forecasts: mid-latitude surface air temperature and heat wave events. Clim. Dyn. https://doi.org/10.1007/s00382-018-4221-4 (2018).

99. Zampieri, L., Goessling, H. F. \& Jung, T. Bright prospects for Arctic sea ice prediction on subseasonal time scales. Geophys. Res. Lett. 45, 9731-9738 (2018).

100. Zampieri, L., Goessling, H. F. \& Jung, T. Predictability of Antarctic sea ice edge on subseasonal time scales. Geophys. Res. Lett. 46, 9719-9727 (2019). 
101. Bushuk, M. et al. A mechanism for the Arctic sea ice spring predictability barrier. Geophys. Res. Lett. https://doi.org/10.1029/2020GL088335 (2020).

102. Kimmritz, M. et al. Impact of ocean and sea ice initialisation on seasonal prediction skill in the Arctic. JAMES https://doi.org/10.1029/2019MS001825 (2019).

103. Ono, J., Komuro, Y. \& Tatebe, H. Impact of sea-ice thickness initialized in April on Arctic sea-ice extent predictability with the MIROC climate model. Ann. Glaciol. 61, 97-105 (2020).

104. Liu, J. et al. Towards reliable Arctic sea ice prediction using multivariate data assimilation. Sci. Bull. 64, 63-72 (2019).

105. Jung, T. et al. Advancing polar prediction capabilities on daily to seasonal time scales. Bull. Am. Meteorol. Soc. 97, 1631-1647 (2016).

106. Jung, T., Kasper, M. A., Semmler, T. \& Serrar, S.

Arctic influence on subseasonal midlatitude prediction. Geophys. Res. Lett. $41,3676-3680(2014)$.

107. Baldwin, M. P. et al. Stratospheric memory and skill of extended-range weather forecasts. Science 301, 636-640 (2003).

108. Butler, A. H., Polvani, L. M. \& Deser, C. Separating the stratospheric and tropospheric pathways of El Nino- Southern Oscillation teleconnections. Environ. Res. Lett https://doi.org/10.1088/1748-9326/9/2/024014 (2014). 109. Sigmond, M. et al. Enhanced seasonal forecast skill following stratospheric sudden warmings. Nat. Geosci. 6, 98-102 (2013).

110. Scaife, A. A. et al. Seasonal winter forecasts and the stratosphere. Atmos. Sci. Lett $\mathrm{https}: / /$ doi.org/10.1002/ asl.598 (2016). 
1120

1121

1122

1123

1124

1125

1126

1127

1128

1129

1130

1131

1132

1133

1134

1135

1136

1137

1138

1139

1140

1141

1142

1143

111. Anstey, J. A. \& Shepherd, T. G. High-latitude influence of the quasi-biennial oscillation (Review article). Quart. J. Roy. Meteorol. Soc. 140, 1-21 (2014).

112. Garfinkel, C. I. \& Hartmann, D. L. Influence of the quasi-biennial oscillation on the North Pacific and El Niño teleconnections. J. Geophys. Res. 115, D20116 (2010). 113. Wang, J., Kim, H. -M. \& Chang, E. K. M.

Interannual modulation of northern hemisphere winter storm tracks by the QBO. Geophys. Res. Lett. 45, 2786-2794 (2018).

114. Yoo, C. \& Son, S.-W. Modulation of the boreal wintertime Madden-Julian

Oscillation by the stratospheric quasi-biennial oscillation. Geophys. Res. Lett. 43, 1392-1398 (2016).

115. Son, S.-W., Lim, Y., Yoo, C., Hendon, H. H. \& Kim, J. Stratospheric control of Madden-Julian Oscillation. J. Clim. 30, 1909-1922 (2017).

116. Lim, Y. et al. Influence of the QBO on MJO prediction skill in the subseasonalto-seasonal prediction models. Clim. Dyn. https://doi.org/10.1007/s00382-01904719-y (2019).

117. Tompkins, A. M. et al. The climate-system historical forecast project: providing open access to seasonal forecast ensembles from centers around the globe. Bull. Am. Meteorol. Soc. 98(11), 2293-2301 (2017).

118. Acosta Navarro, J. C. et al. Link between autumnal Arctic sea ice and northern hemisphere winter forecast skill. Geophys. Res. Lett. 47, e2019GL086753 (2020). 119. Scaife, A. A. et al. Skill of tropical rainfall predictions in multiple seasonal forecast systems. Int. J. Climatol. https://doi.org/10.1002/joc.5855 (2018). 120. Hu, Z. et al. How much of monthly mean precipitation variability over global land is associated with SST anomalies? Clim. Dyn. 54, 701-712 (2020). 
1146 (Springer, 2013).

1147 122. Capotondi, A., Wittenberg, A. T., Kug, J.-S., Takahashi, K. \& McPhaden, M. J., 1148 in El Niño Southern Oscillation in a Changing Climate (eds McPhaden, M., Santoso, 1149 A. \& Cai, W.) 65-86 (AGU, 2020).

1150 123. Vimont, D. J., Alexander, M. A. \& Newman, M. Optimal growth of central and 1151 east Pacific ENSO events. Geophys. Res. Lett. 41, 4027-4034 (2014).

1152 124. Zhang, H., Clement, A. \& DiNezio The south Pacific meridional mode: a 1153 mechanism for ENSO-like variability. J. Clim. 27, 769-783 (2014).

1154 125. Larson, S. \& Kirtman, B. P. The Pacific meridional mode as a trigger for ENSO 1155 in a high-resolution coupled model. Geophys. Res. Lett. https://doi.org/ 10.1002/grl.50571 (2013).

1157 126. Capotondi, A. \& Sardeshmukh, P. D. Optimal precursors of different types of 1158 ENSO events. Geophys. Res. Lett. 42, 9952-9960 (2015).

1159 127. Amaya, D. The Pacific meridional mode and ENSO: a review. Curr. Clim. 1160 Change Rep. https://doi.org/ 10.1007/s40641-019-00142-x (2019).

1161 128. Larson, S. M. \& Kirtman, B. P. Assessing Pacific Meridional Mode forecasts 1162 and its role as an ENSO precursor and predictor in the North American multi-model 1163 ensemble. J. Clim. 27, 7018-7032 (2014).

1164 129. Ren, H. F.-F., Jin, B. \& \& Tian, A. A. Scaife distinct persistence barriers in two 1165 types of ENSO. Geophys. Res. Lett. 43, 10,973-10,979 (2016).

1166 130. Infanti, J. M. \& Kirtman, B. P. North American rainfall and temperature 1167 prediction response to the diversity of ENSO. Clim. Dyn. https://doi.org/10.1007/ 1168 s00382-015-2749-0 (2016). 
1169

1170

1171

1172

1173

1174

1175

1176

1177

1178

1179

1180

1181

1182

1183

1184

1185

1186

1187

1188

1189

1190

1191

1192

1193

131. DiNezio, P. et al. A two-year forecast for a $60-80 \%$ chance of La Nina in $2017-$ 2018. Geophys. Res. Lett. https://doi.org/10.1002/2017GL074904 (2017).

132. Freund, M. B. et al. Higher frequency of central Pacific El Niño events in recent decades relative to past centuries. Nat. Geosci. 12, 450-455 (2019).

133. McPhaden, M. J. Genesis and evolution of the 1997-98 El Niño. Science 283, 950-954 (1999). 134. Capotondi, A., Sardeshmukh, P. D. \& Ricciardulli, L.

The nature of the stochastic wind forcing of ENSO.

J. Clim. 31, 8081-8099 (2018).

135. Tan, X. et al. A study of the effects of westerly wind

bursts on ENSO based on CESM. Clim. Dyn. 54, 885-899 (2020).

136. Lopez, H. \& WWBs, B. P. K. ENSO predictability, the spring barrier and extreme events. J. Geophys. Res. Atmos. 119, 10,114-10,138 (2014).

137. Ren, H. L. et al. Seasonal predictability of winter ENSO types in operational dynamical model predictions. Clim. Dyn. 52, 3869-3890 (2019).

138. Chang, P. et al. Climate fluctuations of tropical coupled systems: the role of ocean dynamics. J. Clim. 19, 5122-5174 (2006).

139. Lübbecke, J. F. \& McPhaden, M. J. Symmetry of the Atlantic Niño mode.

Geophys. Res. Lett. 44, 965-973 (2017).

140. Richter, I. et al. On the link between mean state biases and prediction skill in the tropics: an atmospheric perspective. Clim. Dyn. 50, 3355-3374 (2018).

141. Stockdale, T. N., Balmaseda, M. A. \& Vidard, A. Tropical Atlantic SST

prediction with coupled ocean-atmosphere GCMs. J. Clim. 19, 6047-6061 (2006).

142. Ding, H. et al. The impact of mean state errors on equatorial Atlantic interannual variability in a climate model. J. Geophys. Res. Oceans 120, 1133-1151 (2015). 
1194

1195

1196

1197

1198

1199

1200

1201

1202

1203

1204

1205

1206

1207

1208

1209

1210

1211

1212

1213

1214

1215

1216

1217

1218

143. Saji, N. H., Goswami, B. N., Vinayachandran, P. N. \& Yamagata, T. A dipole mode in the tropical Indian Ocean. Nature 401, 360-363 (1999).

144. Krishnamurthy, V. \& Kirtman, B. P. Variability of the Indian Ocean: relation to monsoon and ENSO. Q. J. R. Meteorol. Soc. 129, 1623-1646 (2003).

145. Wu, R., Kirtman, B. P. \& Krishnamurthy, V. An asymmetric mode of tropical Indian Ocean rainfall variability in boreal spring. J. Geophys. Res. Atmos.

https://doi.org/10.1029/2007JD009316 (2008).

146. Lu, B. et al. An extreme negative Indian Ocean dipole event in 2016: dynamics and predictability. Clim. Dyn. https://doi.org/10.1007/s00382-017-3908-2 (2017).

147. Shinoda, T. \& Han, W. Influence of Indian Ocean dipole on atmospheric subseasonal variability. J. Clim. 18, 3891-3909 (2005).

148. Dunstone, N. et al. Skilful predictions of the winter North Atlantic Oscillation one year ahead. Nat. Geosci. 9, 809-814 (2016).

149. Dunstone, N. et al. Skilful seasonal predictions of summer European rainfall. Geophys. Res. Lett. 45, 3246-3254 (2018).

150. Paolino, D. A., Kinter, J. L., Kirtman, B. P., Min, D. \& Straus, D. M. The impact of land surface and atmospheric initialization on seasonal forecasts with CCSM. $J$. Clim. 25, 1007-1021 (2011).

151. Dirmeyer, P. A. The role of the land surface background state in climate predictability. J. Hydrometeorol. 4, 599-610 (2003).

152. Prodhomme, C., Doblas-Reyes, F., Bellprat, O. \& Dutra, E. Impact of landsurface initialization on sub-seasonal to seasonal forecasts over Europe. Clim. Dyn. 47, 919-935 (2016).

153. Ardilouze, C., Batté, L., Decharme, B. \& Déqué, M.

On the link between summer dry bias over the US Great Plains and seasonal 
temperature prediction skill in a dynamical forecast system. Weather Forecast. 34, 1161-1172 (2019).

154. Marshall, A. G. \& Scaife, A. A. Improved predictability of stratospheric sudden warming events in an atmospheric general circulation model with enhanced stratospheric resolution. J. Geophys. Res. 115, D16114 (2010).

155. Boer, G. J. \& Hamilton, K. QBO influence on extratropical predictive skill. Clim. Dyn. 31, 987-1000 (2008).

156. Marshall, A. G. \& Scaife, A. A. Impact of the QBO on surface winter climate. J. Geophys. Res. 114, D18110 (2009).

157. Scaife, A. A. et al. Predictability of the Quasi-Biennial Oscillation and its northern winter teleconnection on seasonal to decadal timescales. Geophys. Res. Letts. $41,1752-1758$ (2014).

158. Doblas-Reyes, F. J., Hagedorn, R., Palmer, T. N. \& Morcrette, J.-J. Impact of increasing greenhouse gas concentrations in seasonal ensemble forecasts. Geophys. Res. Lett. 33, L07708 (2006).

159. Solaraju-Murali, B., Caron, L.-P., González-Reviriego, N. \& Doblas-Reyes, F. J. Multi-year prediction of European summer drought conditions for the agricultural sector. Environ. Res. Lett. https:// doi.org/10.1088/1748-9326/ab5043 (2019). 160. Cassou, C. et al. Decadal climate variability and predictability: challenges and opportunities. Bull. Am. Meteorol. Soc. 99, 479-490 (2018).

161. Liu, Z. \& Di Lorenzo, E. Mechanisms and predictability of Pacific decadal variability. Curr. Clim. Chang. Rep. 4, 128-144 (2018).

162. Power, S., Casey, T., Folland, C., Colman, A. \& Mehta, V. Inter-decadal modulation of the impact of ENSO on Australia. Clim. Dyn. 15, 319-324 (1999). 
163. Mantua, N. J., Hare, S. R., Zhang, Y., Wallace, J. M. \& Francis, R. C.

A Pacific interdecadal climate oscillation with impacts on salmon production. Bull. Am. Meteorol. Soc. 78, 1069-1079 (1997).

164. Newman, M. et al. The Pacific Decadal Oscillation, revisited. J. Clim. 29, 4399-4427 (2016).

165. Chiang, J. C. H. \& Vimont, D. J. Analogous Pacific and Atlantic Meridional Modes of tropical atmosphere- ocean variability. J. Clim. 17, $4143-4158$ (2004).

166. Di Lorenzo, E. et al. North Pacific Gyre Oscillation links ocean climate and ecosystem change. GRL 35, L08607 (2008).

167. Han, W. et al. Indian Ocean decadal variability: a review. Bull. Am. Meteor. Soc. 95, 1679-1703 (2014).

168. Han, W. et al. Intensification of decadal and multi- decadal sea level variability in the western tropical Pacific during recent decades. Clim. Dyn. 43, 1357-1379 (2014).

169. Li, Y., Han, W., Wang, F., Zhang, L. \& Duan, J. Vertical structure of the upper-Indian Ocean thermal variability. J. Clim. 33, 7233-7253 (2020).

170. Tozuka, T., Luo, J., Masson, S. \& Yamagata, T. Decadal modulations of the Indian Ocean dipole in the SINTEX- F1 coupled GCM. J. Clim. 20, 2881-2894 (2007).

171. Feng, M. H. H. et al. Decadal increase in Ningaloo Niño since the late 1990s. Geophys. Res. Lett. 42, 104-112 (2015).

172. Ummenhofer, C. C., Biastoch, A. \& Böning, C. W. Multi-decadal Indian Ocean variability linked to the Pacific and implications for preconditioning Indian Ocean Dipole events. J. Clim. 30, 1739-1751 (2017). 
173. Lee, S.-K. et al. Pacific origin of the abrupt increase in Indian Ocean heat content during the warming hiatus. Nat. Geosci 8, 445-450 (2015).

174. Nieves, V., Willis, J. K. \& Patzert, W. C. Recent hiatus caused by decadal shift in Indo-Pacific heating. Science 349, 532-535 (2015).

175. Jin, X. et al. Distinct mechanisms of decadal subsurface heat content variations in the eastern and western Indian Ocean modulated by tropical Pacific SST. J. Clim. 31, 7751-7769 (2018).

176. Annamalai, H., Potemra, J., Murtugudde, R. \& McCreary, J. P. Effect of preconditioning on the extreme climate events in the tropical Indian Ocean. J. Clim. 18, 3450-3469 (2005).

177. Henley, B. J. et al. Spatial and temporal agreement in climate model simulations of the Interdecadal Pacific Oscillation. Environ. Res. Lett. 12, 044011 (2017).

178. Fasullo, J. T., Phillips, A. S. \& Deser, C. Evaluation of leading modes of climate variability in the CMIP archives. J. Clim. https://doi.org/10.1175/JCLI-D-19- 1024.1 (2020).

179. Mann, M. E., Steinman, B. A. \& Miller, S. K. Absence of internal multidecadal and interdecadal oscillations in climate model simulations. Nat. Commun. https:// doi.org/10.1038/s41467-019-13823-w (2020).

180. Kosaka, Y.\& Xie, S.-P. The tropical Pacific as a key pacemaker of the variable rates of global warming. Nat. Geosci. https://doi.org/10.1038/NGEO2770 (2016).

181. Tung, K.-K. \& Chen, X. Understanding the recent global surface warming slowdown: a review. Climate 6, 82 (2018). 
182. England, M. H. et al. Recent intensification of wind- driven circulation in the Pacific and the ongoing warming hiatus. Nat. Clim. Change 4, 222-227 (2014).

183. Meehl, G. A., Teng, H. \& Arblaster, J. M. Climate model simulations of the observed early-2000s hiatus of global warming. Nat. Clim. Change 4, 898-902 (2014).

184. Fyfe, J. C. et al. Making sense of the early-2000s warming slowdown. Nat. Clim. Change 6, 224-228 (2016).

185. Xie, S.-P. \& Kosaka,, Y. What caused the global surface warming hiatus of 1998-2013? Curr. Clim. Change Rep. 3, 128-140 (2017).

186. Seager, R. et al. Strengthening tropical Pacific zonal sea surface temperature gradient consistent with rising greenhouse gases. Nat. Clim. Change. 9, 517-522 (2019).

187. Chen, X. \& Tung, K.-K. Varying planetary heat sink led to globalwarming slowdown and acceleration. Science 345, 897-903 (2014).

188. Santer, B. D. et al. Observed multivariable signals of late 20th and early 21 st century volcanic activity. Geophys. Res. Lett. 42, 500-509 (2015). recent global surface warming slowdown. Nat. Clim. Chang. 6, 936 (2016).

190. Oudar, T., Kushner, P. J., Fyfe, J. \& Sigmond, M. No impact of anthropogenic aerosols on early 21 st century global temperature trends in a large initial-condition ensemble. Geophys. Res. Lett. 45, 9245-9252 (2018). 191. Guemas, V., Doblas-Reyes, F. J., Andreu-Burillo, I. \& Asif, M. Retrospective prediction of the global warming slowdown in the past decade. Nat. Clim. Change 3, 649-653 (2013). 
192. Bordbar, M. H. et al. Uncertainty in near-term global surface warming linked to tropical Pacific climate variability. Nat. Commun. 10, 1990 (2019).

193. Meehl, G. A., Chung, C. T. Y., Arblaster, J. M., Holland, M. M. \& Bitz, C. M. Tropical decadal variability and the rate of Arctic sea ice retreat. Geophys. Res. Lett. https://doi.org/10.1029/2018GL079989 (2018).

194. Meehl, G. A., Arblaster, J. M., Bitz, C., Chung, C. T. Y. \& Teng, H. Antarctic sea ice expansion between 2000-2014 driven by tropical Pacific decadal climate variability. Nat. Geosci https://doi.org/10.1038/ NGEO2751 (2016).

195. Purich, A. et al. Tropical Pacific SST drivers of recent Antarctic sea ice trends. $J$. Clim. 29, 8931-8948 (2016).

196. Thoma, M., Greatbatch, R. J., Kadow, C. \& Gerdes, R. Decadal hindcasts initialized using observed surface wind stress: evaluation and prediction out to 2024 . Geophys. Res. Lett. 42, 6454-6461 (2015).

197. Meehl, G. A. et al. Recent sudden Antarctic sea ice retreat caused by connections to the tropics and sustained ocean changes around Antarctica.

Nat. Commun. 10, 14 (2019).

198. Yin, J., Overpeck, J., Peyser, C. \& Stouffer, R. Big jump of record warm global mean surface temperature in 2014-2016 related to unusually large oceanic heat releases. Geophys. Res. Lett. 45, 1069-1078 (2018).

199. Booth, B. B. B., Dunstone, N. J., Halloran, P. R., Andrews, T. \& Bellouin, N. Aerosols implicated as a prime driver of twentieth-century North Atlantic climate variability. Nature 484, 228 (2012).

200. Watanabe, M. \& Tatebe, H. Reconciling roles of sulphate aerosol forcing and internal variability in Atlantic multidecadal climate changes. Clim. Dyn. 53, 46514665 (2019). 
201. Hermanson, L. et al. Robust multiyear climate impacts of volcanic eruptions in decadal prediction systems. J. Geophys. Res. Atmos. https://doi.org/10.1029/2019JD031739 (2020).

202. Menary, M. B. \& Scaife, A. A. Naturally forced multidecadal variability of the Atlantic meridional overturning circulation. Clim. Dyn. 42, 1347-1362 (2014). 203. Cai, W. et al. Pantropical climate interactions. Science 363, eaav4236 (2019). 204. Mechoso, R. (ed.) Interacting Climates of Ocean Basins: Observations, Mechanisms, Predictability, and Impacts (Cambridge Univ. Press, 2020). 205. Meehl, G. A. et al. Atlantic and Pacific tropics connected by mutually interactive decadal-timescale processes. Nat. Geosci. https://doi.org/10.1038/s41561-020-00669$\mathrm{x}(2020)$.

206. Chikamoto, Y. et al. Skillful multi-year predictions of tropical trans-basin climate variability. Nat. Commun. 6, 6869 (2015).

207. Ruprich-Robert, Y. et al. Assessing the climate impacts of the observed Atlantic multidecadal variability using the GFDL CM2.1 and NCAR CESM1 global coupled models. J. Clim. 30, 2785-2810 (2017).

208. Levine, A. F. Z., McPhaden, M. J. \& Frierson, D. M. W. The impact of the AMV on multidecadal ENSO variability. Geophys. Res. Lett. 44, 3877-3886 (2017). 209. Kumar, A., Bhaskar, J. \& Wang, H. Attribution of SST variability in global oceans and the role of ENSO. Clim. Dyn. 43, 209-220 (2014).

210. Taschetto, A. S., Rodrigues, R. R., Meehl, G. A., McGregor, S. \& England, M. H. How sensitive are the Pacific-North Atlantic teleconnections to the position and intensity of El Niño-related warming. Clim. Dyn. https://doi.org/10.1007/s00382-0152679-x (2015). 
211. Han, W. et al. Decadal variability of Indian and Pacific Walker Cells: do they covary on decadal timescales? J. Clim. 30, 8447-8468 (2017).

212. Han, W. et al. Multi-decadal trend and decadal variability of the regional sea level over the Indian Ocean since the 1960s: roles of climate modes and external forcing. Climate 6, 51 (2018).

213. Deepa, J. S. et al. The tropical Indian Ocean decadal sea level response to the Pacific decadal oscillation forcing. Clim. Dyn. 52, 5045 (2019).

214. Zhang, R. et al. A review of the role of the Atlantic meridional overturning circulation in Atlantic multidecadal variability and associated climate impacts. Rev. Geophys. 57, 316-375 (2019).

215. Li, X., Xie, S.-P., Gille, S. T. \& Yoo, C. Atlantic-induced pan-tropical climate change over the past three decades. Nat. Clim. Change https://doi.org/10.1038/ NCLIMATE2840 (2015).

216. Li, H., Ilyina, T., Müller, W. A. \& Seinz, F. Decadal prediction of the North Atlantic CO2 uptake. Nat. Commun. 7, 11076 (2016).

217. Jin, D. \& Kirtman, B. P. How the annual cycle affects the extratropical response to ENSO. J. Geophys. Res. 115, D06102 (2010).

218. Zhang, L., Han, W. \& Sienz, F. Unraveling causes for the changing behavior of tropical Indian Ocean in the past few decades. J. Clim. 31, 2377-2388 (2018).

219. Thornton, H. et al. Skillful seasonal prediction of winter gas demand. Env. Res. Lett. 14, 024009 (2019).

220. Palin, E. J. et al. Skillful seasonal forecasts of winter disruption to the U.K. transport system. J. Appl. Meteor. Climatol. 55, 325-344 (2016).

221. Towler, E., Paimazumder, D. \& Done, J. Toward application of decadal climate predictions. J. Appl. Meteorol. Climatol. 57, 555-568 (2018). 
222. Vecchi, G. A. et al. On the seasonal forecasting of regional tropical cyclone activity. J. Clim. 27, 7994-8016 (2014).

223. Annan, J. D. et al. Parameter estimation in an atmospheric GCM using the ensemble Kalman filter. Nonlinear Processes Geophys. https://doi.org/ 10.5194/npg12-363-2005 (2005).

224. Düben, P. D., Hugh McNamara, H. \& Palmer, T. N. The use of imprecise processing to improve accuracy in weather \& climate prediction. J. Comput. Phys. $271,2-18$ (2014).

225. Palmer, T. N., Peter Düben, P. \& McNamara, H. Stochastic modelling and energy-efficient computing for weather and climate prediction. Phil. Trans. Roy. Soc. $A$ https://doi.org/10.1098/rsta.2014.0118 (2014).

226. Ham, Y.-G., Kim, J.-H. \& Luo, J.-J. Deep learning for multi-year ENSO forecasts. Nature https://doi.org/ 10.1038/s41586-019-1559-7 (2019).

227. Zhang, S. et al. Coupled data assimilation and parameter estimation in coupled ocean-atmosphere models: a review. Clim. Dyn. 54, 5127-5144 (2020). 228. Karspeck, A. R. et al. A global coupled ensemble data assimilation system using the community earth system model and the data assimilation research testbed. Q. J. R. Meteorol. Soc. 144, 2404-2430 (2018).

229. Mulholland, D., Laloyaux, P., Haines, K. \& Balmaseda, M. Origin and impact of initialization shocks in coupled atmosphere-ocean forecasts. Monthly Weather. Rev. 143, 4631-4644 (2015).

230. Saha, S. et al. The NCEP climate forecast system reanalysis. Bull. Am. Meteorol. Soc. 91, 1015-1057 (2010).

231. Laloyaux, P. et al. A coupled data assimilation system for climate reanalysis. $Q$. J. R. Meteorol. Soc. 142, 65-78 (2016). 
232. Herman, R. J. et al. The effects of anthropogenic and volcanic aerosols and greenhouse gases on twentieth century Sahel precipitation. Sci. Rep. 10, 12203 (2020).

233. Schurer, A., Hegerl, G., Mann, M. E. \& Tett, S. F. B. Separating forced from chaotic climate variability over the past millennium. J. Clim. 26, 6954-6973 (2013). 234. Ault, T. R. et al. The continuum of hydroclimate variability in western North America during the last millennium. J. Clim. 26, 5863-5878 (2013). 235. Laepple, T. \& Huybers, P. Global and regional variability in marine surface temperatures. Geophys. Res. Lett. 41, 2528-2534 (2014).

236. Loope, G., Thompson, D. M., Cole, J. E. \& Overpeck, J. Is there a lowfrequency bias in multiproxy reconstructions of Pacific SST variability? Quat. Sci. Rev. 246, 106530 (2020).

237. Frankignoul, C., Muller, P. \& Zorita, E. A simple model of the decadal response of the ocean to stochastic wind forcing. J. Phys. Oceanogr. 27, 1533-1546 (1997). 238. Capotondi, A., Alexander, M. A. \& Deser, C. Why are there Rossby wave maxima in the Pacific at 10S and 13N? J. Phys. Oceanogr. 33, 1549-1563 (2003). 239. Chikamoto, Y., Timmermann, A., Widlansky, M. J., M. A., \& L. Multi-year predictability of climate, drought, and wildfire in southwestern North America. Sci. Rep. https://www.ncbi.nlm.nih.gov/pubmed/28747719 (2017).

240. Lovenduski, N. S., Bonan, G. B., Yeager, S. G., Lindsay, K. \& Lombardozzi, D. L. High predictability of terrestrial carbon fluxes from an initialized decadal prediction system. Environ. Res. Lett. 14, 124074 (2019). 241. Sospedra-Alfonso, R., Merryfield, W. J. \& Kharin, V. V. Representation of snow in the Canadian seasonal to interannual prediction system: part II. Potential predictability and hindcast skill. J. Hydrometeorol. 17, 2511-2535 (2016). 
242. Kapnick, S. B. et al. Potential for western US seasonal snowpack prediction. Proc. Natl Acad. Sci. USA 115, 1180-1185 (2018).

243. Holbrook, N. J. et al. Keeping pace with marine heatwaves. Nat. Rev. Earth Environ. 1, 482-493 (2020).

244. Batté, L. et al. Summer predictions of Arctic sea ice edge in multimodel seasonal re-forecasts. Clim. Dyn. 54, 5013-5029 (2020).

245. Subramanian, A., Juricke, S., Dueben, P. \& Palmer, T. A stochastic representation of subgrid uncertainty for dynamical core development. Bull. Am. Meteorol. Soc. 100, 1091-1101 (2019).

246. Penny, S. G. et al. Observational needs for improving ocean and https://doi.org/ 10.3389/fmars.2019.00391 (2019).

247. Lofverstrom et al. An efficient ice-sheet/Earth System model spin-up procedure for CESM2.1 and CISM2.1: description, evaluation, and broader applicability. JAMES https://doi.org/10.1029/2019MS001984 (2020).

248. Gettelman, A. et al. The Whole Atmosphere Community Climate Model version 6(WACCM6). J. Geophys. Res. Atmos. https://doi.org/10.1029/2019JD030943 (2019).

249. Tommasi, D. C. et al. Managing living marine resources in a dynamic environment: the role of seasonal to decadal climate forecasts. Prog. Oceanogr. 152, 15-49 (2017). 250. Stock, C. A. et al. Seasonal sea surface temperature anomaly prediction for coastal ecosystems. Prog. Oceanogr. 137, 219-236 (2015). 
251. Liu, G. et al. Predicting heat stress to inform reef management: NOAA Coral Reef Watch's 4-month coral bleaching outlook. Front. Mar. Sci. https://doi.org/ 10.3389/fmars.2018.00057 (2018).

252. Capotondi, A., Sardeshmukh, P. D., Di Lorenzo, E., Subramanian, A. \& Miller, A. J. Predictability of US West Coast ocean temperatures is not solely due to ENSO. Sci. Rep. 9, 10993 (2019).

253. Wells, M. L. et al. Harmful algal blooms and climate change: learning from the past and present to forecast the future. Harmful Algae 49, 68-93 (2015).

254. Séférian, R. et al. Multiyear predictability of tropical marine productivity. Proc. Natl Acad. Sci. USA 111, 11646-11651 (2014).

255. Park, J.-Y., Stock, C. A., Dunne, J. P., Yang, X. \& Rosati, A. Seasonal to multiannual marine ecosystem prediction with a global Earth System model. Science 365, 284-288 (2019).

256. Krumhardt, K. M. et al. Potential predictability of net primary production in the ocean. Glob. Biogeochem. Cycles 34, e2020GB006531 (2020).

257. Siedlecki, S. A. et al. Experiments with seasonal forecasts of ocean conditions for the northern region of the California Current upwelling system. Sci. Rep. 6, 1-18 (2016).

258. Brady, R. X., Lovenduski, N. S., Yeager, S. G., Long, M. C. \& Lindsay, K. Skillful multiyear predictions of ocean acidification in the California Current System. Nat. Commun. 11, 2166 (2020).

259. Séférian, R., Berthet, S. \& Chevallier, M. Assessing the decadal predictability of land and ocean carbon uptake. Geophys. Res. Lett. 45, 2455-2466 (2018). 
260. Lovenduski, N. S., Yeager, S. G., Lindsay, K. \& Long, M. C. Predicting nearterm variability in ocean carbon uptake. Earth Syst. Dyn. 10, 45-57 (2019).

261. Li, H., Ilyina, T., Müller, W. A. \& Landschützer, P. Predicting the variable ocean carbon sink. Sci. Adv. https://doi.org/10.1126/sciadv.aav6471 (2019).

262. Bett, P. E. et al. Skillful seasonal prediction of key carbon cycle components:

NPP and fire risk. Environ. Res. Commun. 2, 055002 (2020).

263. Park, J.-Y., Dunne, J. P. \& Stock, C. A. Ocean chlorophyll as a precursor of

ENSO: an earth system modeling study. Geophys. Res. Lett. https://doi.org/

10.1002/2017GL076077 (2018).

264. Capotondi, A. et al. Observational needs supporting marine ecosystem modeling and forecasting: from the global ocean to regional and coastal systems. Front. Mar. Sci. 6, 623 (2019).

265. Fennel, K. et al. Advancing marine biogeochemical and ecosystem reanalyses and forecasts as tools for monitoring and managing ecosystem health. Front. Mar. Sci. 6, 89 (2019).

266. Weisheimer, A. \& Palmer, T. N. On the reliability of seasonal climate forecasts. J. R. Soc. Interface https://doi.org/10.1098/rsif.2013.1162 (2014).

267. National Academies of Sciences, Engineering and Medicine. Next Generation Earth System Prediction: Strategies for Subseasonal to Seasonal Forecasts 1-351 (National Academies Press, 2017). 268. National Research Council. Assessment of Intraseasonal to Interannual Climate Prediction and Predictability 1-193 (National Academies Press, 2010). 269. Mehta, V. Natural Decadal Climate Variability: Phenomena, Mechanisms, and Predictability 1-374 (CRC Press, 2020). 
1513

1514

1515

1516

1517

1518

1519

1520

1521

1522

1523

1524

1525

1526

1527

1528

1529

1530

1531

1532

1533

1534

1535

1536

270. GISTEMP Team, 2020: GISS Surface Temperature Analysis (GISTEMP), version 4. NASA Goddard Institute for Space Studies Dataset accessed 2021-02-25 at https://data.giss.nasa.gov/gistemp/ (2020).

271. Lenssen, N. J. L. et al. Improvements in the GISTEMP Uncertainty Model. J. Geophys. Res. Atmos. 124, 6307-6326 (2019).

\section{Acknowledgements}

The foundations of this paper emerged from a workshop held by National Academies of Sciences, Engineering and Medicine in 2015 at Woods Hole, MA, and the authors gratefully acknowledge support from Amanda Purcell and Nancy Huddleston t.

Portions of this study were supported by the Regional and Global Model Analysis (RGMA) component of the Earth and Environmental System Modeling Program of the U.S. Department of Energy's Office of Biological \& Environmental Research (BER) via National Science Foundation IA 1844590. This work also was supported by the National Center for Atmospheric Research, which is a major facility sponsored by the National Science Foundation under Cooperative Agreement No. 1852977.

M.E.M. was supported by a grant from the NSF Paleoclimate Program \#1748097.

F.J.D.R. and M.G.D. were supported by the H2020 EUCP project under Grant agreement no. 776613, M.G.D also by the Ramón y Cajal 2017 grant reference RYC2017-22964. A.C. acknowledges support from the NOAA Climate Program Office's Modeling Analysis, Prediction and Projection Program (grant \# NA17OAR4310106) and from the NOAA Climate Program Office's Climate Variability and Predictability Program. A.C.S. acknowledges support from the NOAA Climate Variability and 
Predictability Program (Award NA18OAR4310405) and the National Oceanic and Atmospheric Administration (NOAA-MAPP; NA17OAR4310106) for support. N.S.L. is grateful for support from the NSF (OCE-1752724). D.M.T. acknowledges support from NCAR Advanced Study Program and NSF (OCE-1931242). S.C.S was supported by the Joint Institute for the Study of the Atmosphere and Ocean (JISAO) Postdoctoral Fellowship.

\section{Author contributions}

H.T. suggested the original concept. G.A.M. led the overall conceptual design, and coordinated the writing. J.H.R. and H.T. made major contributions to the conceptual design and organization. J.H.R. generated Fig. 1a. H.T. generated Fig. 4. All authors discussed the concepts presented and contributed to the writing.

\section{Competing Interests}

The authors declare no competing interests.

(1)


Table 1. General characteristics of models used for S2S, S2I and S2D initialized

\begin{tabular}{|c|c|c|c|c|c|c|c|}
\hline Timescale & $\begin{array}{l}\text { Number } \\
\text { of } \\
\text { models }\end{array}$ & $\begin{array}{l}\text { Atmospheric } \\
\text { resolution \& } \\
\text { levels }\end{array}$ & $\begin{array}{l}\text { Ocean } \\
\text { resolutionlevels }\end{array}$ & $\begin{array}{l}\text { Components } \\
\text { initialized }\end{array}$ & $\begin{array}{l}\text { Initiali- } \\
\text { zation }\end{array}$ & $\begin{array}{l}\text { Number } \\
\text { of } \\
\text { ensembles }\end{array}$ & $\begin{array}{l}\text { Prediction } \\
\text { length }\end{array}$ \\
\hline S2S & 18 & $\begin{array}{l}25-200 \mathrm{~km} \\
17-91 \text { levels }\end{array}$ & $\begin{array}{l}8-200 \mathrm{~km} \\
25-75 \text { levels }\end{array}$ & $\begin{array}{l}\text { Most } \\
\text { initialize } \\
\text { atmosphere, } \\
\text { ocean, land } \\
\text { and sea ice }\end{array}$ & $\begin{array}{l}\text { Full } \\
\text { field }\end{array}$ & $4-51$ & $\begin{array}{l}31-62 \\
\text { days }\end{array}$ \\
\hline S2I & 13 & $\begin{array}{l}36-200 \mathrm{~km} \\
24-95 \text { levels }\end{array}$ & $\begin{array}{l}25-200 \mathrm{~km} \\
24-74 \text { levels }\end{array}$ & $\begin{array}{l}\text { All initialize } \\
\text { atmosphere, } \\
\text { ocean, land } \\
\text { and sea ice }\end{array}$ & $\begin{array}{l}\text { Full } \\
\text { field }\end{array}$ & $10-51$ & $\begin{array}{l}6-12 \\
\text { months }\end{array}$ \\
\hline S2D & 14 & $\begin{array}{l}50-200 \mathrm{~km} \\
26-95 \text { levels }\end{array}$ & $\begin{array}{l}25-100 \mathrm{~km} \\
30-75 \text { levels }\end{array}$ & $\begin{array}{l}\text { Models } \\
\text { range from } \\
\text { initializing } \\
\text { only ocean, } \\
\text { to } \\
\text { initializing } \\
\text { atmosphere, } \\
\text { ocean, land } \\
\text { and sea ice }\end{array}$ & $\begin{array}{l}\text { Full } \\
\text { field, } \\
\text { anomaly }\end{array}$ & $10-40$ & $\begin{array}{l}5-10 \\
\text { years }\end{array}$ \\
\hline
\end{tabular}

*A full and more complete accounting of model features is given in Supplementary

1561 Table 1, 2 and 3 for S2S, S2I and S2D models. 
a)

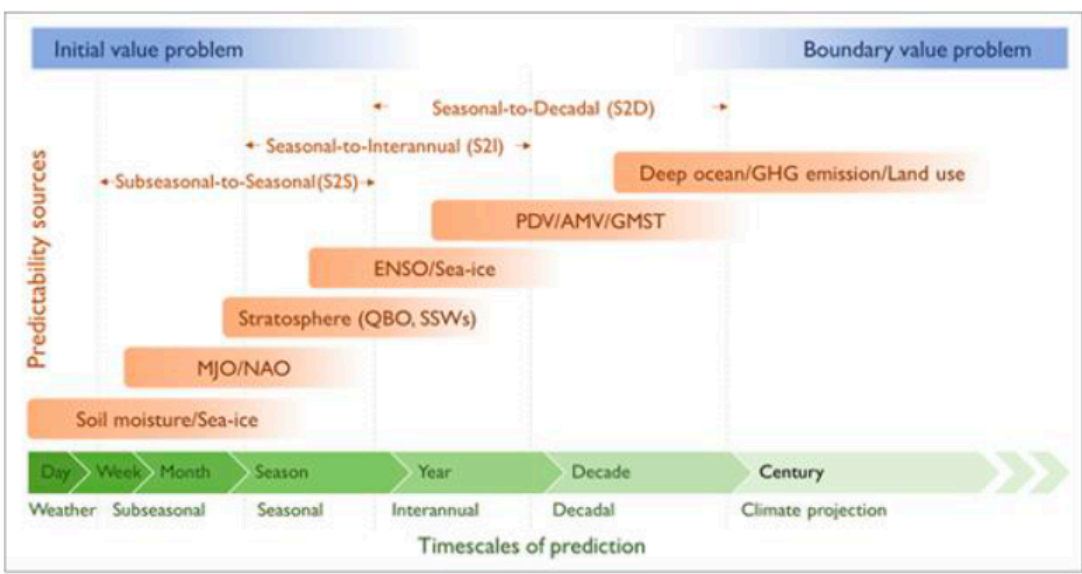

b)

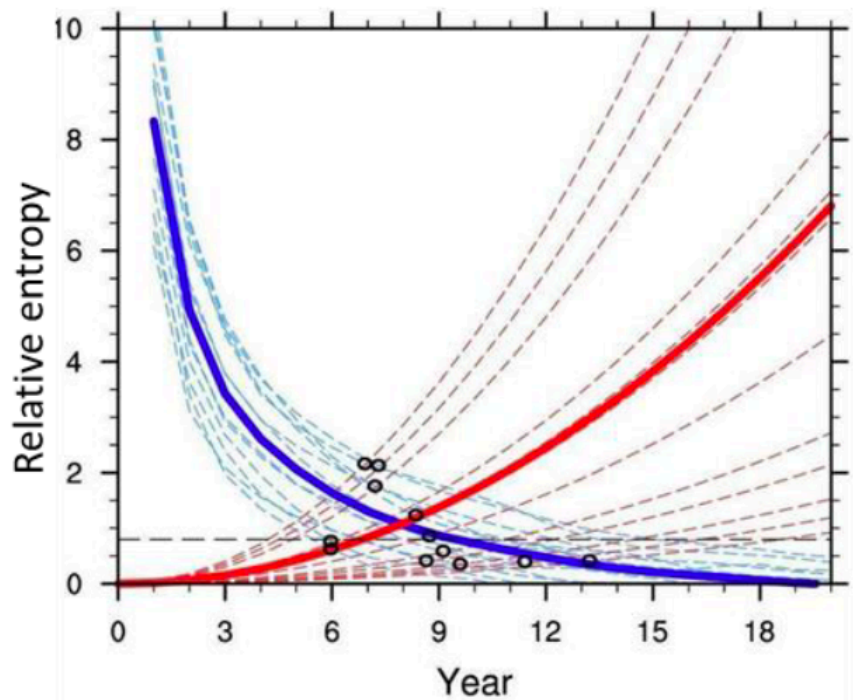

1563 Figure 1. Timescales and processes involved with initialized predictions. a

1564 Timescales and sources of predictability for S2S, S2I, and S2D. Lighter green shading 1565 indicates larger uncertainty. MJO: Madden-Julian Oscillation; NAO: North Atlantic

1566 Oscillation; QBO: Quasi-Biennial Oscillation; SSWs: Sudden Stratospheric

1567 Warmings; ENSO: El Nino-Southern Oscillation; PDW: Pacific Decadal Variability;

1568 AMV: Atlantic Multi-decadal variability; GMST: Global Mean Surface Temperature;

1569 GHG: Greenhouse Gas. b| skill in predicting the upper 300m of the Atlantic Ocean

1570 temperature, as measured by relative entropy, in initialized models (blue) and those

1571 forced by RCP4.5 (red). Skill is high for initialized predictions at S2S and S2I 
1573 from external forcing increases. Panel $\mathrm{b}$ adapted, with permission, from ref $\mathrm{x}$

1574 (Branstator and Teng, 2012).

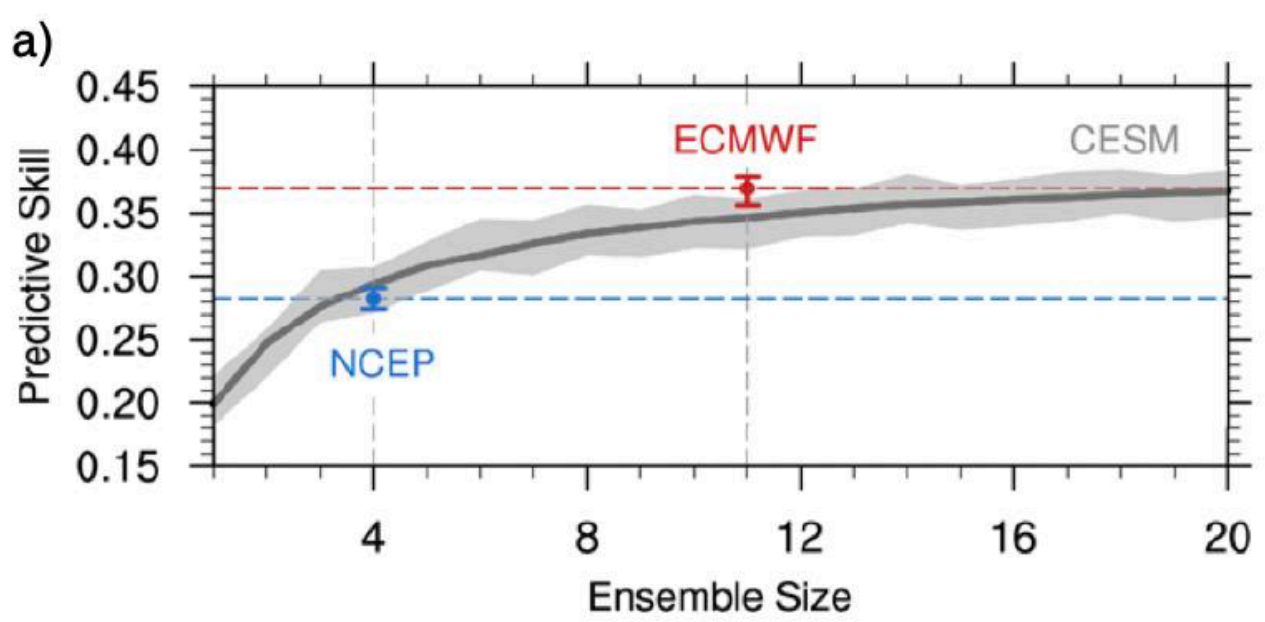

b)

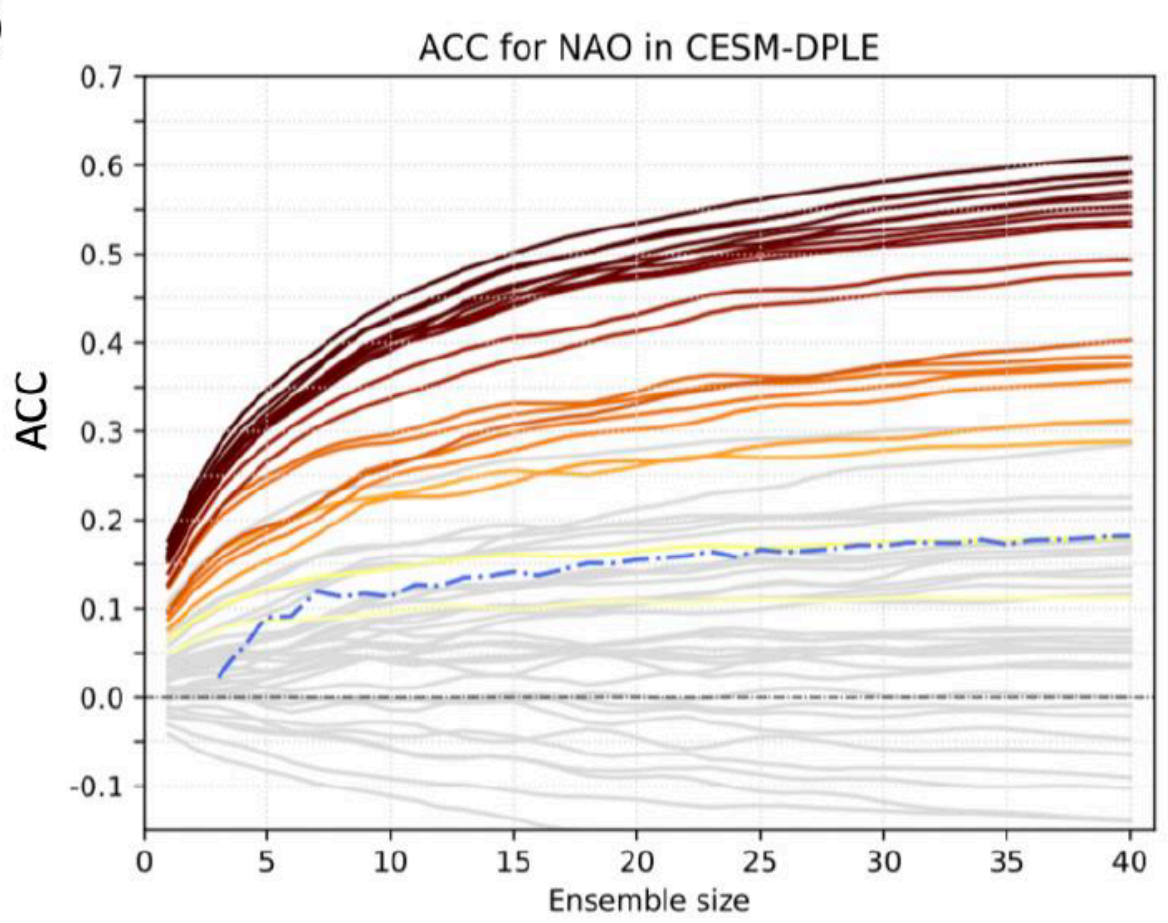

1577 Figure 2. Influence of ensemble size and lead year ranges on predictive skill. a|

1578 Skill (as measured by anomaly correlation coefficient) in predicting S2S globally 
averaged NDJFM surface air temperature (excluding the Antarctic) from CESM

1580 initialized hindcasts of various ensemble size (grey line). Shading denotes the 5\% and $158195 \%$ significance levels. Blue and red whiskers illustrate predictive skill for NCEP

1582 CFSv2 and ECMWF subseasonal hindcasts, respectively (Kim et al., 2019b).ADD

1583 TAKE HOME MESSAGE. b| Skill (as measured by the anomaly correlation

1584 coefficient) in predicting S2D wintertime NAO using ensembles of different sizes

1585 from the Decadal Prediction Large Ensemble (DPLE). Each line depicts a different

1586 lead year range, with those that are colored corresponding to statistically significant

1587 correlations; the darker the shading, the greater the statistical signifance. The dashed-

1588 dotted line shows the skill of the sub-ensemble mean against a single member of the

1589 ensemble (averaged for all possible combinations). The more ensemble members, the

1590 higher the skill for longer lead year ranges. Panel $\mathrm{b}$ adapted, with permission, from ref

1591 (Athanasiadis et al., 2020). 


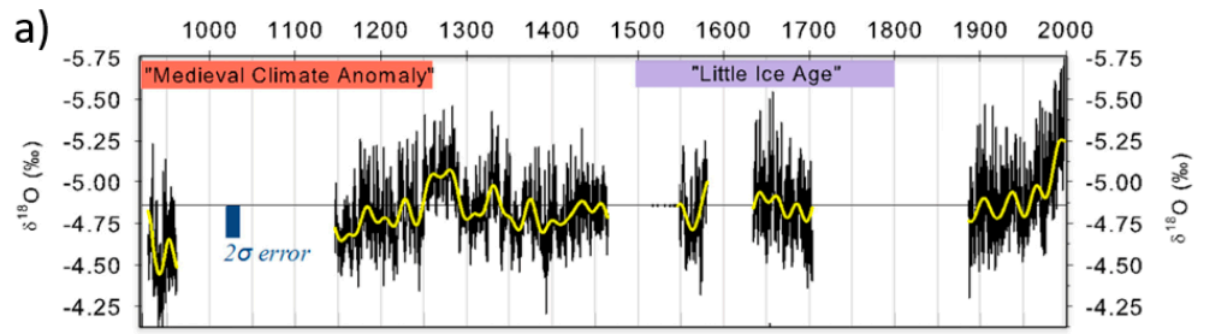

b)

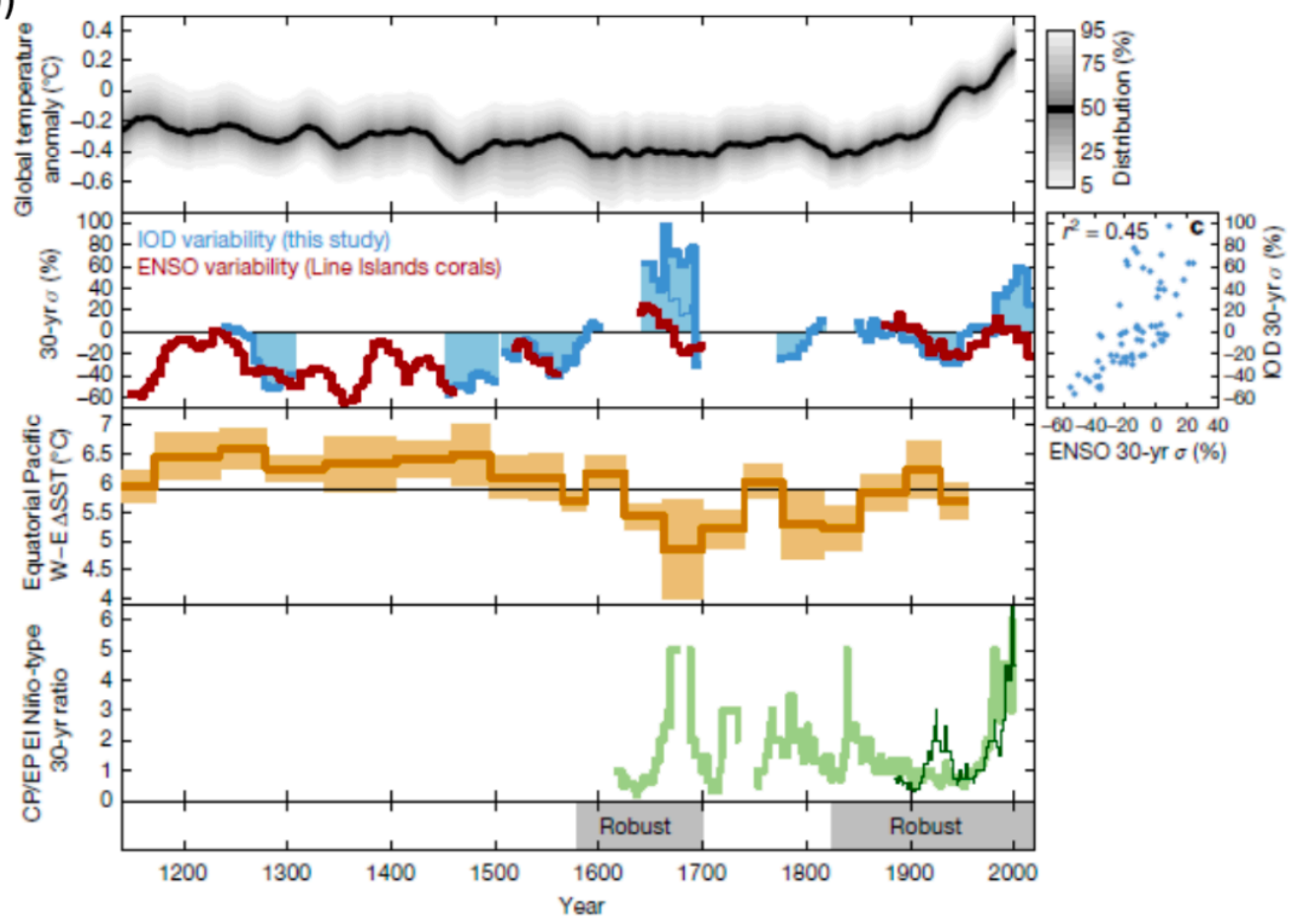

Figure 3. Extending proxy observations of S2D variability back in time. a |

1594 Global mean surface temperature anomalies, b | 30 year running means of the coral1595 based Indian Ocean Dipole (IOD) (blue) and El Nino-Southern Oscillation (ENSO) 1596 (red); $\mathbf{c} \mid$ scatter plot of coral-based IOD and ENSO; $\mathbf{d} \mid$ equatorial Pacific west-east 1597 SST gradient ; e | central and eastern Pacific El Niño derived from teleconnected 1598 climate patterns. $\mathbf{f} \mid \mathbf{x x x x x}$. Collective, the figures illustrate a strengthening of IOD1599 ENSO decadal variability after $\sim 1590$. Figure adapted, with permission, from ref $\mathrm{x}$ 1600 (Abram et al., 2020). 


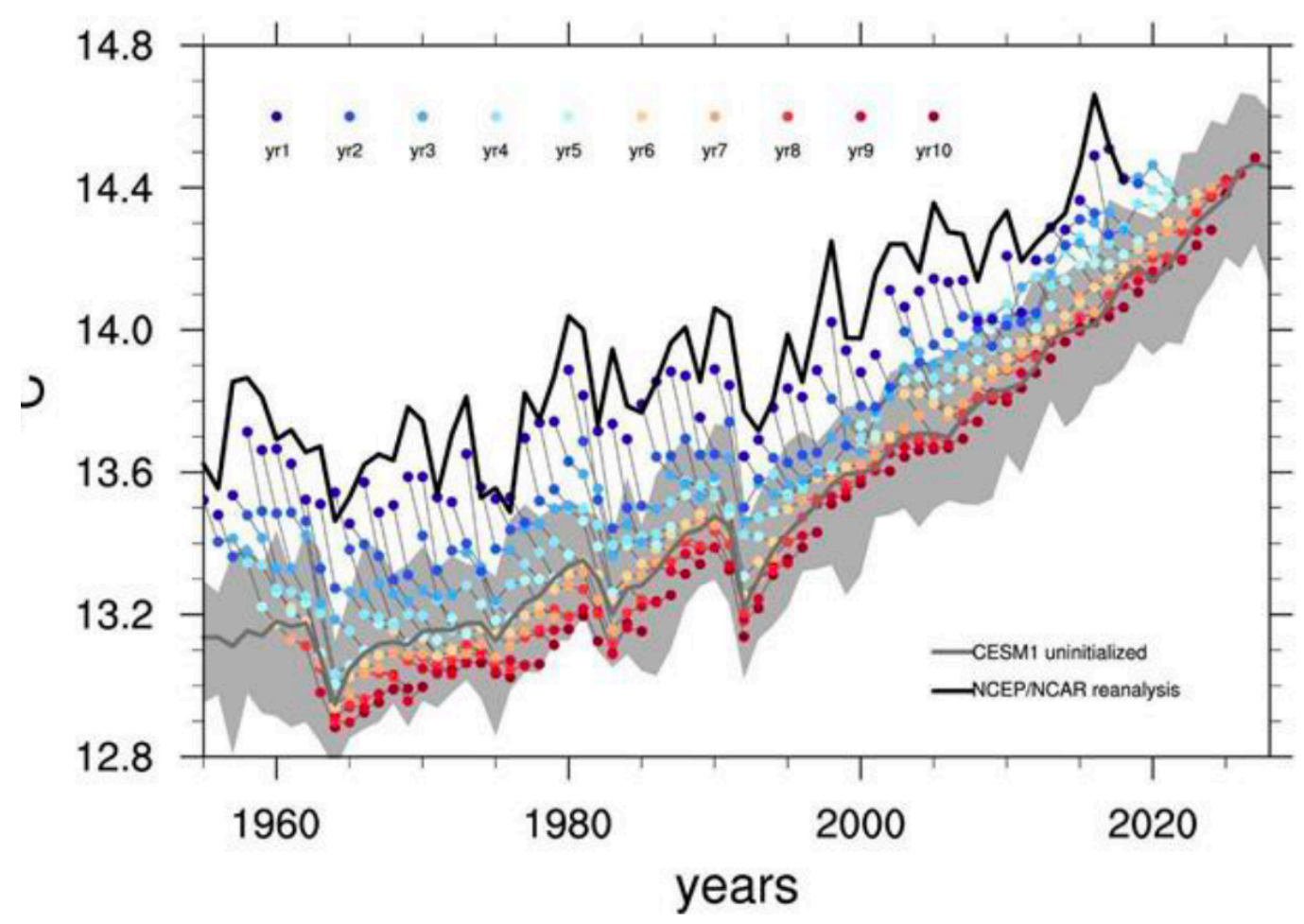

1602

1603 Figure 4. Impact of model drift on initialized predictions. Globally averaged

1604 surface temperature predictions from the Decadal Prediction Large Ensemble (Yeager

1605 et al., 2018) as a function of simulation year. Initial state predictions (blue dots)

1606 compare well to observations (black line), but drift (progression of blue dots to red

1607 dots) toward the model's systematic error state represented by the uninitialized state

1608 (dark gray line; gray shading is range of uninitialized projections). 


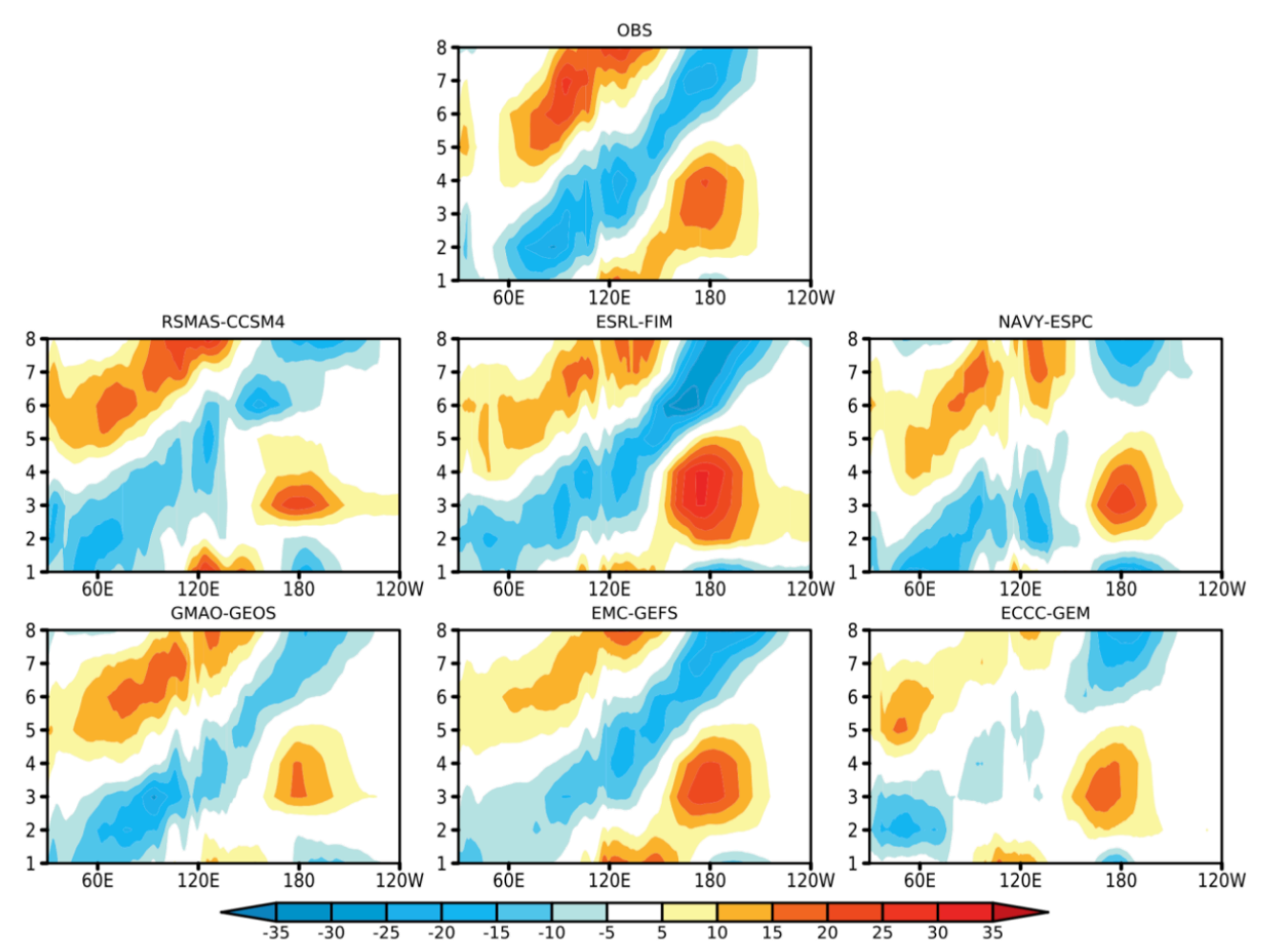

1610

1611 Figure 5. Initialized S2S predictions of the MJO. a | observed outgoing longwave

1612 radiation (OLR) anomalies averaged over $5^{\circ} \mathrm{S}$ to $5^{\circ} \mathrm{N}$ as a function of the stage of the

1613 Madden-Julian Oscillation (MJO). b-g $\mid$ as in $\mathbf{a}$, but for various initialized predictions,

1614 with OLR anomalies taken as the average of simulations days 15-21. MJO events are

1615 identified based on RMM index amplitude $\geq 1$. The eastward propagation of MJO-

1616 related OLR anomalies is well captured by all six models. Figure adapted, with

1617 permission, from ref $\mathrm{x}$ (Pegion et al., 2019). 
a)

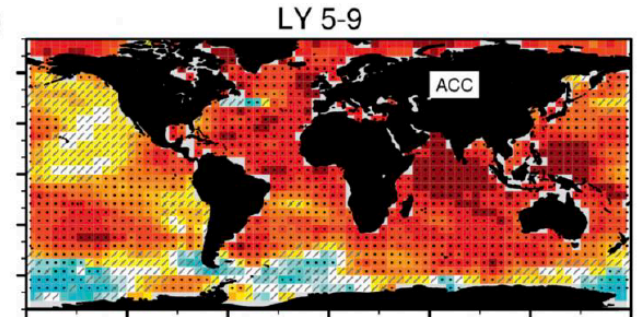

b)

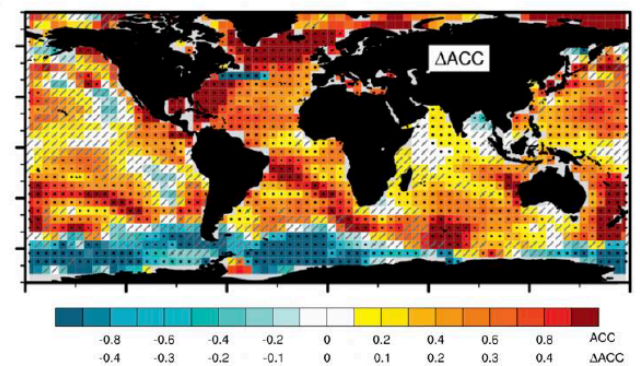

c)

d)
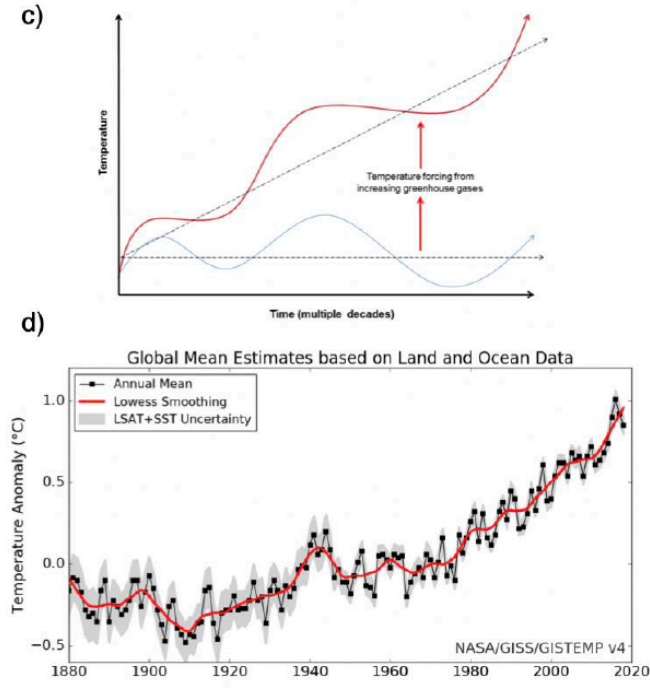

1619

Figure 6. Skill of S2D predictions involves credible simulation of aspects of timeevolving globally averaged temperature. a| Prediction skill, measured as the anomaly correlation coefficient, of sea surface temperature (SST) averaged over years 5-9 from a decadal prediction large ensemble; darker red indicates higher skill. b| improvement in prediction skill associated with $\mathrm{xxxx}$; darker red indicates better skill in the initialized predictions. ADD TAKE HOME MESSAGE. c) Schematic of the "rising staircase", illustrating how natural decadal-scale temperature fluctuations (blue) are tilted upwards owing to anthropogenic greenhouse gas emissions (red), producing accelerated warming in some decades, and reduced warming in others. d) time series of observed global mean surface temperature anomalies showing characteristics of the rising staircase: accelerated warming over 1980-2000 and 2014present, and a slow-down in the rate of warming over 2000-2014. Panels a and b adapted, with permission, from ref $\mathrm{x}$ (Yeager et al., 2018). Panel c adapted, with permission, from ref $\mathrm{x}$ (Kosaka and Xie, 2016). Panel d adapted, with permission, from NASA 
1638 Supplementary Table 1. Main characteristics of 18 currently used S2S initialized

1639 prediction models. The table provides a general survey of $\mathrm{S} 2 \mathrm{~S}$, and is not intended to provide detailed documental of each model. Modeling center acronyms are described in the Appendix; origin refers to model originating either in the climate community (C) or from Numerical Weather Prediction (NWP) community; Operational or Research model is depicted by $\mathrm{O}$ and $\mathrm{R}$ respectively; Approximate atmospheric and ocean model horizontal resolution (current) is provided either in degrees, kilometers, or begins with ' $T$ ' for spectral models, number of vertical levels begins with ' $L$ '; The existence of ocean and sea-ice coupling is indicated by ' $\mathrm{Y}$ ' (yes) or ' $\mathrm{N}$ ' (no); Model components initialized with a state representative of observations are indicated by ' $A$ ' for the atmosphere, ' $\mathrm{L}$ ' for land, ' $\mathrm{O}$ ' for ocean, and 'I' for sea-ice; Initialization type refers to either 'Full-field (FF)' or 'Anomaly(A).' Initialization frequency for real time forecasts and reforecasts is indicated separately and often in different time units. '\# Ens' indicates the number of ensemble members for real time forecasts and reforecasts (Rfc); Forecast length is specified in number of days. Superscripts in the modeling center column depict the following: 1 indicates models included in the international S2S database, 2 indicates models included in the SubX project. ${ }^{*}$ indicates that the full CFSv2 data (6 hourly initializations) are provided to the S2S database. The SubX version is a subset based on the SubX protocol (weekly initialization). For models that have used multiple versions and/or configurations, most recent configuration is described.

\begin{tabular}{|c|c|c|c|c|c|c|c|c|c|c|c|}
\hline $\begin{array}{l}\text { Model- } \\
\text { ing } \\
\text { Center }\end{array}$ & $\begin{array}{l}\text { Model } \\
\text { Name }\end{array}$ & $\begin{array}{l}\text { Orig } \\
\text { in } \\
\text { (Cli- } \\
\text { mate } \\
\text { or } \\
\text { NW } \\
\text { P) }\end{array}$ & $\begin{array}{l}\begin{array}{l}\text { Ops. } \\
\text { or } \\
\text { Re- }\end{array} \\
\text { searc } \\
\text { h }\end{array}$ & $\begin{array}{l}\text { Atmos. } \\
\text { Resolut } \\
\text { ion } \\
\text { /Vertic } \\
\text { al } \\
\text { Levels }\end{array}$ & $\begin{array}{l}\text { Ocean } \\
\text { Res./ } \\
\text { Levels }\end{array}$ & $\begin{array}{l}\text { Ocean/ } \\
\text { Sea Ice } \\
\text { Coupli } \\
\text { ng }\end{array}$ & $\begin{array}{l}\text { Compo- } \\
\text { nents } \\
\text { Initial- } \\
\text { ized }\end{array}$ & Init & $\begin{array}{l}\text { Data } \\
\text { Assimilation }\end{array}$ & $\begin{array}{l}\text { Init. Frequency } \\
\text { (Real time/Rfc) }\end{array}$ & $\begin{array}{l}\text { \# En } \\
\text { Real } \\
\text { time } \\
\text { Rfc }\end{array}$ \\
\hline \multicolumn{12}{|c|}{ Models Providing Real Time Forecasts and Reforecasts } \\
\hline $\mathrm{BoM}^{1}$ & $\begin{array}{l}\text { ACCESS- } \\
\text { S1 }\end{array}$ & $\mathrm{C}$ & $\mathrm{O}$ & $\begin{array}{l}\text { N216, } \\
\text { L85 }\end{array}$ & $\begin{array}{l}0.25 \mathrm{o} / \\
\mathrm{L} 75\end{array}$ & $\mathrm{Y} / \mathrm{Y}$ & $\mathrm{A}, \mathrm{L}, \mathrm{O}, \mathrm{I}$ & $\mathrm{FF}$ & $\begin{array}{l}\text { Nudging } \\
\text { from } 4 \mathrm{dVar}\end{array}$ & Daily, 4 per month & $33 / 1:$ \\
\hline
\end{tabular}




\begin{tabular}{|c|c|c|c|c|c|c|c|c|c|c|c|}
\hline $\mathrm{CMA}^{1}$ & $\begin{array}{l}\text { BCC- } \\
\text { CSM2-HR }\end{array}$ & $\mathrm{C}$ & $\mathrm{O}$ & $\begin{array}{l}\text { T266, } \\
\text { L56 }\end{array}$ & $\begin{array}{l}0.25^{\circ} / \\
\mathrm{L} 50\end{array}$ & $\mathrm{Y} / \mathrm{Y}$ & $\mathrm{A}, \mathrm{O}, \mathrm{I}$ & $\mathrm{FF}$ & $\begin{array}{l}\text { Coupled DA } \\
\text { (ocean: } \\
\text { EnOI; sea } \\
\text { ice: OI; } \\
\text { atmos: } \\
\text { nudging) }\end{array}$ & Daily/Daily & $\begin{array}{l}4 \\
14\end{array}$ \\
\hline $\begin{array}{l}\text { CNR- } \\
\text { ISAC }^{1}\end{array}$ & GLOBO & $\mathrm{C}$ & $\mathrm{O}$ & $\begin{array}{l}0.8^{\circ} \mathrm{x} \\
0.56^{\circ}, \\
\text { L54 }\end{array}$ & $\mathrm{N} / \mathrm{A}$ & $\mathrm{N} / \mathrm{N}$ & $\mathrm{A}, \mathrm{L}$ & $\mathrm{FF}$ & N/A & weekly/every 5 days & $41 / 1$ \\
\hline $\mathrm{ECCC}^{1,2}$ & $\begin{array}{l}\text { GEPS, } \\
\text { GEM }\end{array}$ & & $\mathrm{O}$ & $\begin{array}{l}0.45^{\circ} \times 0 \\
.45^{\circ} / \\
\mathrm{L} 40\end{array}$ & N/A & $\mathrm{N} / \mathrm{N}$ & A, L & $\mathrm{FF}$ & EnKF & weekly/weekly & $21 / 4$ \\
\hline $\begin{array}{l}\text { ECMWF } \\
1\end{array}$ & ECMWF & $\begin{array}{l}\text { NW } \\
\mathrm{P}\end{array}$ & $\mathrm{O}$ & $\begin{array}{l}0.25^{\circ} \mathrm{x} 0 \\
.25^{\circ} \\
(\text { days } 0- \\
10) \\
0.5^{\circ} \mathrm{x} 0 . \\
5^{\circ}(\text { after } \\
\text { day10) } \\
/ \text { L91 }\end{array}$ & $\begin{array}{l}0.25^{\circ} / \\
\mathrm{L} 75\end{array}$ & $\mathrm{Y} / \mathrm{N}$ & $\mathrm{A}, \mathrm{L}, \mathrm{O}$ & $\mathrm{FF}$ & $\begin{array}{l}\text { 4D Var } \\
\text { (atmosphere; } \\
\text { 3D VAR } \\
\text { (ocean/sea- } \\
\text { ice) }\end{array}$ & $\begin{array}{l}2 \text { per week } / 2 \text { per } \\
\text { week }\end{array}$ & $51 / 1:$ \\
\hline $\mathrm{HMCR}^{1}$ & SLAV & $\begin{array}{l}\text { NW } \\
\text { P }\end{array}$ & $\mathrm{O}$ & $\begin{array}{l}1.1^{\circ} \times 1 \\
4^{\circ} / \mathrm{L} 28\end{array}$ & $\mathrm{~N} / \mathrm{A}$ & $\mathrm{N} / \mathrm{N}$ & A & $\mathrm{FF}$ & 3D Var & Weekly/weekly & $20 / 11$ \\
\hline $\mathrm{JMA}^{1}$ & $\begin{array}{l}\text { JMA } \\
\text { GEPS, } \\
\text { GSM }\end{array}$ & $\begin{array}{l}\text { NW } \\
\mathrm{P}\end{array}$ & $\mathrm{O}$ & $\begin{array}{l}0.5^{\circ} \times 0 . \\
5^{\circ} / \mathrm{L} 60\end{array}$ & N/A & $\mathrm{N} / \mathrm{N}$ & A, L & $\mathrm{FF}$ & $\begin{array}{l}\text { hybrid } \\
\text { 4DVar- } \\
\text { LETKF }\end{array}$ & $\begin{array}{l}4 \text { per week } / 3 \text { per } \\
\text { month }\end{array}$ & $25 / 5$ \\
\hline $\mathrm{KMA}^{1}$ & $\begin{array}{l}\text { GloSea5- } \\
\text { GC2 }\end{array}$ & $\mathrm{C}$ & $\mathrm{O}$ & $\begin{array}{l}0.5^{\circ} \times 0 . \\
5^{\circ} / \mathrm{L} 85\end{array}$ & $\begin{array}{l}0.25^{\circ} / \\
\mathrm{L} 75\end{array}$ & $\mathrm{Y} / \mathrm{Y}$ & $\mathrm{A}, \mathrm{O}, \mathrm{I}$ & $\mathrm{FF}$ & 4D Var & daily/4 per month & $4 / 3$ \\
\hline $\begin{array}{l}\text { Meteo } \\
\text { France }^{1}\end{array}$ & CNRM-CM & $\mathrm{C}$ & $\mathrm{O}$ & $\begin{array}{l}0.7^{\circ} \times 0 \\
7^{\circ} / \mathrm{L} 91\end{array}$ & $1^{\circ} / \mathrm{L} 42$ & $\mathrm{Y} / \mathrm{Y}$ & $\mathrm{A}, \mathrm{L}, \mathrm{O}, \mathrm{I}$ & $\mathrm{FF}$ & 4D Var & weekly/2 per month & $51 / 1$ \\
\hline
\end{tabular}




\begin{tabular}{|c|c|c|c|c|c|c|c|c|c|c|c|}
\hline $\begin{array}{l}\text { NASA } \\
\text { GMAO }^{2}\end{array}$ & GEOS & $\mathrm{C}$ & $\mathrm{R}$ & $\begin{array}{l}0.5^{\circ} \times 0 . \\
5^{\circ} / \mathrm{L} 72\end{array}$ & $\begin{array}{l}0.5^{\circ} / \\
\mathrm{L} 40\end{array}$ & $\mathrm{Y} / \mathrm{Y}$ & $\mathrm{A}, \mathrm{L}, \mathrm{O}, \mathrm{I}$ & $\mathrm{FF}$ & EnOI & Every 5 days & $4 / 4$ \\
\hline $\mathrm{NAVY}^{2}$ & ESPC & $\mathrm{C}$ & $\mathrm{R}$ & $\begin{array}{l}\text { T359/ } \\
\text { L50 }\end{array}$ & $\begin{array}{l}0.08^{\circ} / \\
41 \mathrm{~L}\end{array}$ & $\mathrm{Y} / \mathrm{Y}$ & $\mathrm{A}, \mathrm{L}, \mathrm{O}, \mathrm{I}$ & $\mathrm{FF}$ & 4DVAR & $\begin{array}{l}4 \text { per week } / 4 \text { per } \\
\text { week }\end{array}$ & $4 / 4$ \\
\hline $\begin{array}{l}\text { NOAA } \\
\text { EMC }^{2}\end{array}$ & GEFS & $\begin{array}{l}\text { NW } \\
\mathrm{P}\end{array}$ & $\mathrm{O}$ & $\begin{array}{l}\text { T574 } \\
\text { (days 0- } \\
8 \text { ), } \\
\text { T382 } \\
\text { (days 8- } \\
\text { 35)/ } \\
\text { L64 }\end{array}$ & N/A & $\mathrm{N} / \mathrm{N}$ & $\mathrm{A}, \mathrm{L}$ & $\mathrm{FF}$ & EnKF & weekly/weekly & $21 / 1$ \\
\hline $\begin{array}{l}\text { NOAA } \\
\text { ESRL }^{2}\end{array}$ & FIM & $\begin{array}{l}\text { NW } \\
\mathrm{P}\end{array}$ & $\mathrm{R}$ & $\begin{array}{l}\sim 60 \\
\mathrm{~km} / \\
\mathrm{L} 64\end{array}$ & $\begin{array}{l}\sim 60 \mathrm{~km} \\
/ \mathrm{L} 32\end{array}$ & $\mathrm{Y} / \mathrm{Y}$ & $\mathrm{A}, \mathrm{L}, \mathrm{O}, \mathrm{I}$ & $\mathrm{FF}$ & N/A & weekly/weekly & $4 / 4$ \\
\hline $\begin{array}{l}\text { NOAA } \\
\text { NCEP }^{1,2}\end{array}$ & CFSv2 & $\mathrm{C}$ & $\mathrm{O}$ & $\begin{array}{l}\text { T126 / } \\
\text { L64 }\end{array}$ & $\begin{array}{l}0.25^{\circ} \mathrm{Eq}, \\
0.5^{\circ} \\
\text { global / } \\
\text { L40 }\end{array}$ & $\mathrm{Y} / \mathrm{Y}$ & A, L, O, I & $\mathrm{FF}$ & 3Dvar & 6 hourly $^{*} / 6$ hourly ${ }^{*}$ & $16 / 1$ \\
\hline RSMAS $^{2}$ & CCSM4 & $\mathrm{C}$ & $\mathrm{R}$ & $\begin{array}{l}0.9^{\circ} \times 1 . \\
25^{\circ} / \\
\text { L26 }\end{array}$ & $\begin{array}{l}0.25^{\circ} \\
\text { Tropics } \\
/ 1^{\circ} \\
\text { global/ } \\
\text { L60 }\end{array}$ & $\mathrm{Y} / \mathrm{Y}$ & $\mathrm{A}, \mathrm{L}, \mathrm{O}, \mathrm{I}$ & $\mathrm{FF}$ & $\mathrm{N} / \mathrm{A}$ & weekly/weekly & $9 / 4$ \\
\hline $\mathrm{UKMO}^{1}$ & GloSea5 & $\mathrm{C}$ & $\mathrm{O}$ & $\begin{array}{l}0.5^{\circ} \times 0 . \\
8^{\circ} / \mathrm{L} 85\end{array}$ & $\begin{array}{l}0.25^{\circ} / \\
\mathrm{L} 75\end{array}$ & $\mathrm{Y} / \mathrm{Y}$ & $\mathrm{A}, \mathrm{L}, \mathrm{O}, \mathrm{I}$ & $\mathrm{FF}$ & 4D Var & Daily/4 per month & $4 / 7$ \\
\hline
\end{tabular}

Models Providing Reforecasts Only 


\begin{tabular}{|c|c|c|c|c|c|c|c|c|c|c|c|}
\hline NCAR & 30LCESM1 & $\mathrm{C}$ & $\mathrm{R}$ & $\begin{array}{l}0.9^{\circ} \times 1 \\
25^{\circ} / \\
\text { L30 }\end{array}$ & $\begin{array}{l}0.25^{\circ} \\
\text { Tropics } \\
/ 1^{\circ} \\
\text { global/ } \\
\text { L60 }\end{array}$ & $\mathrm{Y} / \mathrm{Y}$ & $\mathrm{A}, \mathrm{L}, \mathrm{O}, \mathrm{I}$ & $\mathrm{FF}$ & N/A & weekly & $\mathrm{NA} / 1$ \\
\hline NCAR & 46LCESM1 & $\mathrm{C}$ & $\mathrm{R}$ & $\begin{array}{l}0.9^{\circ} \times 1 \\
25^{\circ} / \\
\text { L30 }\end{array}$ & $\begin{array}{l}0.25^{\circ} \\
\text { Tropics } \\
/ 1^{\circ} \\
\text { global/ } \\
\text { L60 }\end{array}$ & $\mathrm{Y} / \mathrm{Y}$ & $\mathrm{A}, \mathrm{L}, \mathrm{O}, \mathrm{I}$ & $\mathrm{FF}$ & N/A & weekly & $\mathrm{NA} / 1$ \\
\hline
\end{tabular}

models. The table provides a general survey of S2I, and is not intended to provide

1668 detailed documental of each model Column labels are the same as in Table S1, except

1669 forecast length is in months. ${ }^{3}$ indicates models participating in the NMME. ${ }^{4}$ depicts models contributing to the Copernicus Climate Change Service (C3S).

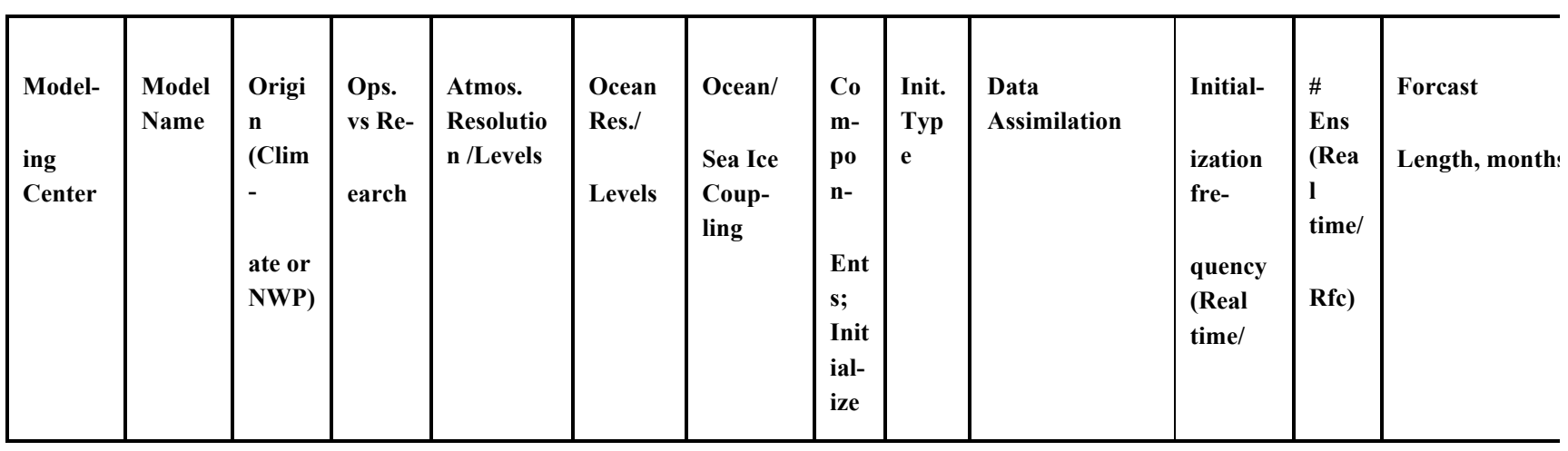




\begin{tabular}{|c|c|c|c|c|c|c|c|c|c|c|c|}
\hline & & & & & & & d & & Rfe) & & \\
\hline BOM & $\begin{array}{l}\text { ACCE } \\
\text { SS-S1 }\end{array}$ & $\mathrm{C}$ & $\mathrm{O}$ & N216/L85 & $\begin{array}{l}0.250 \\
/ L 75\end{array}$ & $\mathrm{Y} / \mathrm{Y}$ & $\begin{array}{l}\text { A, } \\
\text { L, } \\
\text { O,I }\end{array}$ & $\mathrm{FF}$ & $\begin{array}{l}\text { Daily/4 } \\
\text { per } \\
\text { month }\end{array}$ & $\begin{array}{l}11 / 1 \\
1\end{array}$ & 7 \\
\hline $\mathrm{CMCC}$ & $\begin{array}{l}\mathrm{CMCC} \\
-\mathrm{SPS}^{4}\end{array}$ & $\mathrm{C}$ & $\mathrm{O}$ & $1^{\circ} / \mathrm{L} 46$ & $\begin{array}{l}0.25^{\circ} \\
/ \mathrm{L} 50\end{array}$ & $\mathrm{Y} / \mathrm{Y}$ & $\begin{array}{l}\mathrm{A}, \\
\mathrm{L}, \\
\mathrm{O}, \mathrm{I}\end{array}$ & $\mathrm{FF}$ & $\begin{array}{l}1 \text { st of } \\
\text { the } \\
\text { month }\end{array}$ & $\begin{array}{l}50 / 4 \\
0\end{array}$ & 6 \\
\hline DWD & $\begin{array}{l}\text { MPI- } \\
\text { ESP }^{4}\end{array}$ & $\mathrm{C}$ & $\mathrm{O}$ & $\begin{array}{l}\text { T127 / } \\
\text { L95 }\end{array}$ & $\begin{array}{l}0.4^{\circ} \mathrm{Eq} \\
/ \mathrm{L} 40\end{array}$ & $\mathrm{Y} / \mathrm{Y}$ & $\begin{array}{l}\mathrm{A}, \\
\mathrm{L}, \\
\mathrm{O}, \mathrm{I}\end{array}$ & $\mathrm{FF}$ & $\begin{array}{l}1 \text { st of } \\
\text { the } \\
\text { month }\end{array}$ & $\begin{array}{l}50 / 3 \\
0\end{array}$ & 12 \\
\hline ECCC & $\begin{array}{l}\mathrm{CanC} \\
{\mathrm{M} 4 \mathrm{i}^{3}}^{3}\end{array}$ & $\mathrm{C}$ & $\mathrm{O}$ & T63 / L35 & $\begin{array}{l}.94^{\circ} \mathrm{Eq} / \\
\mathrm{L} 40\end{array}$ & $\mathrm{Y} / \mathrm{Y}$ & $\begin{array}{l}\mathrm{A}, \\
\mathrm{L}, \\
\mathrm{O}, \mathrm{I}\end{array}$ & $\mathrm{FF}$ & $\begin{array}{l}1 \text { st of } \\
\text { the } \\
\text { month }\end{array}$ & $\begin{array}{l}10 / 1 \\
0\end{array}$ & 12 \\
\hline ECCC & $\begin{array}{l}\text { GEM- } \\
\text { NEMO } \\
3\end{array}$ & NWP & $\mathrm{O}$ & $1.4^{\circ} / \mathrm{L} 79$ & $\begin{array}{l}0.33^{\circ} \mathrm{Eq} \\
/ 1^{\circ} \text { glob } \\
\text { al/ L50 }\end{array}$ & $\mathrm{Y} / \mathrm{Y}$ & $\begin{array}{l}\text { A, } \\
\text { L, } \\
\text { O, I }\end{array}$ & $\mathrm{FF}$ & $\begin{array}{l}1 \text { st of } \\
\text { the } \\
\text { month }\end{array}$ & $\begin{array}{l}10 / 1 \\
0\end{array}$ & 12 \\
\hline $\begin{array}{l}\text { ECMW } \\
\text { F }\end{array}$ & $\begin{array}{l}\text { SEAS5 } \\
4\end{array}$ & NWP & $\mathrm{O}$ & $\begin{array}{l}\mathrm{TCo} 319 \\
(36 \mathrm{~km}) / \mathrm{L} 9 \\
1\end{array}$ & $\begin{array}{l}0.25^{\circ} \\
/ \mathrm{L} 75\end{array}$ & $\mathrm{Y} / \mathrm{Y}$ & $\begin{array}{l}\text { A, } \\
\text { L, } \\
\text { O, I }\end{array}$ & $\mathrm{FF}$ & $\begin{array}{l}1 \text { st of } \\
\text { the } \\
\text { month }\end{array}$ & $\begin{array}{l}51 / 2 \\
5\end{array}$ & $\begin{array}{l}\text { 7(13 from } \\
\text { Feb/May/Aug/N } \\
\text { v) }\end{array}$ \\
\hline
\end{tabular}




\begin{tabular}{|c|c|c|c|c|c|c|c|c|c|c|c|c|}
\hline GFDL & ${ }_{3}^{\text {CM2.1 }}$ & $\mathrm{C}$ & $\mathrm{R}$ & $\begin{array}{l}2 \times 2.5^{\circ} / \\
\mathrm{L} 24\end{array}$ & $\begin{array}{l}2 \times 2.5^{\circ} / \\
\mathrm{L} 24\end{array}$ & $\mathrm{Y} / \mathrm{Y}$ & $\begin{array}{l}\text { A, } \\
\text { L, } \\
\mathrm{O}, \mathrm{I}\end{array}$ & $\mathrm{FF}$ & & $\begin{array}{l}1 \mathrm{st} \text { of } \\
\text { the } \\
\text { month }\end{array}$ & $\begin{array}{l}10 / 1 \\
0\end{array}$ & 12 \\
\hline GFDL & ${ }_{3}^{\mathrm{CM} 2.5}$ & $\mathrm{C}$ & $\mathrm{R}$ & $\begin{array}{l}\mathrm{C} 18(50 \\
\mathrm{km}) / \mathrm{L} 32\end{array}$ & $\begin{array}{l}0.3^{\circ} \mathrm{Eq} / \\
1^{\circ} \\
\text { Polar/ } \\
\text { L50 }\end{array}$ & $\mathrm{Y} / \mathrm{Y}$ & $\begin{array}{l}\text { A, } \\
\text { L, } \\
\mathrm{O}, \mathrm{I}\end{array}$ & $\mathrm{FF}$ & & $\begin{array}{l}1 \mathrm{st} \text { of } \\
\text { the } \\
\text { month }\end{array}$ & $\begin{array}{l}10 / 1 \\
0\end{array}$ & 12 \\
\hline $\begin{array}{l}\text { JMA/ } \\
\text { MRI }\end{array}$ & CPS24 & $\mathrm{C}$ & $\mathrm{O}$ & T159/L60 & $\begin{array}{l}0.3^{\circ} \mathrm{Eq} / \\
\mathrm{L} 52\end{array}$ & $\mathrm{Y} / \mathrm{Y}$ & $\begin{array}{l}\text { A, } \\
\mathrm{L}, \\
\mathrm{O}, \mathrm{I}\end{array}$ & $\mathrm{FF}$ & & $\begin{array}{l}12-13 \\
\text { mem } \\
\text { every } 5 \\
\text { days } / 5 \\
\text { mem } \\
\text { every } \\
15 \text { days }\end{array}$ & $\begin{array}{l}51 / 1 \\
0\end{array}$ & 12 \\
\hline $\begin{array}{l}\text { Météo- } \\
\text { France }\end{array}$ & $\begin{array}{l}\text { System } \\
74\end{array}$ & $\mathrm{C}$ & $\mathrm{O}$ & $\begin{array}{l}\text { TL359/L9 } \\
1\end{array}$ & $\begin{array}{l}0.25^{\circ} \\
/ \mathrm{L} 75\end{array}$ & $\mathrm{Y} / \mathrm{Y}$ & $\begin{array}{l}\text { A, } \\
\text { L, } \\
\text { O, I }\end{array}$ & $\mathrm{FF}$ & & $\begin{array}{l}1 \text { st of } \\
\text { the } \\
\text { month }\end{array}$ & $\begin{array}{l}51 / 2 \\
5\end{array}$ & 7 \\
\hline NASA & $\begin{array}{l}\text { GEOS } \\
{\mathrm{S} 2 \mathrm{~S}^{3}}\end{array}$ & $\mathrm{C}$ & $\mathrm{R}$ & $0.5^{\circ} / \mathrm{L} 72$ & $\begin{array}{l}0.5^{\circ} \mathrm{Eq} / \\
\mathrm{L} 40\end{array}$ & $\mathrm{Y} / \mathrm{Y}$ & $\begin{array}{l}\text { A, } \\
\text { L, } \\
\text { O, I }\end{array}$ & $\mathrm{FF}$ & & $\begin{array}{l}1 \text { mem } \\
\text { ev } 5 \\
\text { days; } 6 \\
\text { member } \\
\text { s on last } \\
\text { day of } \\
\text { month }\end{array}$ & $\begin{array}{l}10 / 1 \\
0\end{array}$ & 10 \\
\hline NCAR & $\begin{array}{l}\text { RSMA } \\
\text { S- } \\
\text { CCSM } \\
4^{3}\end{array}$ & $\mathrm{C}$ & $\mathrm{R}$ & $\begin{array}{l}0.9 \times 1.25^{\circ} \\
\mathrm{L} 26\end{array}$ & $\begin{array}{l}0.25^{\circ} \\
\mathrm{Eq} / \mathrm{L} 60\end{array}$ & $\mathrm{Y} / \mathrm{Y}$ & \begin{tabular}{|l}
$\mathrm{A}$, \\
$\mathrm{L}$, \\
$\mathrm{O}, \mathrm{I}$
\end{tabular} & $\mathrm{FF}$ & N/A & $\begin{array}{l}1 \text { st of } \\
\text { the } \\
\text { month }\end{array}$ & $\begin{array}{l}10 / 1 \\
0\end{array}$ & 12 \\
\hline NCEP & $\underset{3,4}{\mathrm{CFS}}$ & $\mathrm{C}$ & $\mathrm{O}$ & $\begin{array}{l}\text { T126/ } \\
\text { L64 }\end{array}$ & $\begin{array}{l}.25^{\circ} \\
\mathrm{Eq} / \mathrm{L} 40\end{array}$ & $\mathrm{Y} / \mathrm{Y}$ & \begin{tabular}{|l} 
A, \\
L, \\
O, I
\end{tabular} & $\mathrm{FF}$ & & $\begin{array}{l}4 \\
\text { member } \\
\mathrm{s} \text { every } \\
5 \text { days }\end{array}$ & $\begin{array}{l}24 / 2 \\
4\end{array}$ & 10 \\
\hline
\end{tabular}




\begin{tabular}{|c|c|c|c|c|c|c|c|c|c|c|c|}
\hline UKMO & $\begin{array}{l}\text { GloSea } \\
5^{4}\end{array}$ & $\mathrm{C}$ & $\mathrm{O}$ & $\begin{array}{l}0.5^{\circ} \times 0.8^{\circ} / \\
\text { L85 }\end{array}$ & $\begin{array}{l}0.25^{\circ} \\
/ \mathrm{L} 75\end{array}$ & $\mathrm{Y} / \mathrm{Y}$ & $\begin{array}{l}\mathrm{A}, \\
\mathrm{L}, \\
\mathrm{O}, \mathrm{I}\end{array}$ & $\mathrm{FF}$ & $\begin{array}{l}2 \text { per } \\
\text { day/7 } 4 \\
\text { times } \\
\text { per } \\
\text { month }\end{array}$ & $\begin{array}{l}62 / 2 \\
8\end{array}$ & 7 \\
\hline
\end{tabular}

1672

1673 Supplementary Table 3. Main characteristics of 14 S2D initialized prediction

1674 models. The table provides a general survey of S2D, and is not intended to provide

1675 detailed documental of each model. Same as Table S1 but initialization frequency and

1676 ensemble size are used for research except as "operations" denoted via the WMO

1677 Lead Centres, and forecast length is in years.

\begin{tabular}{|c|c|c|c|c|c|c|c|c|c|c|c|}
\hline $\begin{array}{l}\text { Modeling } \\
\text { Center }\end{array}$ & Model Name & $\begin{array}{l}\text { Origin } \\
\text { (Clim } \\
\text { ate or } \\
\text { NWP) }\end{array}$ & $\begin{array}{l}\text { Ops vs } \\
\text { Resear } \\
\text { ch }\end{array}$ & $\begin{array}{l}\text { Atmos. } \\
\text { Res. } \\
\text { /Levels }\end{array}$ & $\begin{array}{l}\text { Ocean } \\
\text { Res. } \\
\text { /Levels }\end{array}$ & $\begin{array}{l}\text { Ocean/ } \\
\text { Sea Ice } \\
\text { Couplin } \\
\text { g }\end{array}$ & $\begin{array}{l}\text { Comp- } \\
\text { onents } \\
\text { initiali } \\
\text { zed }\end{array}$ & $\begin{array}{l}\text { Initiali- } \\
\text { zation } \\
\text { Type }\end{array}$ & $\begin{array}{l}\text { Initiali- } \\
\text { zation } \\
\text { Freque } \\
\text { ncy }\end{array}$ & \begin{tabular}{|l}
$\#$ \\
E \\
ns
\end{tabular} & $\begin{array}{l}\text { For } \\
\text { e- } \\
\text { cast } \\
\text { Dur } \\
- \\
\text { atio } \\
\text { n, } \\
\text { yea } \\
\text { r) }\end{array}$ \\
\hline CCCma & CanESM5 & $\mathrm{C}$ & $\mathrm{R}, \mathrm{O}$ & $2.8^{\circ} / \mathrm{L} 49$ & $1^{\circ}, \mathrm{L} 45$ & $\mathrm{Y} / \mathrm{Y}$ & $\begin{array}{l}\mathrm{A}, \mathrm{L}, \\
\mathrm{O}, \mathrm{I}\end{array}$ & $\mathrm{FF}$ & $\begin{array}{l}\text { End of } \\
\text { each } \\
\text { year }\end{array}$ & 40 & 10 \\
\hline $\begin{array}{l}\text { CCSR/UT } \\
/ \\
\\
\text { JAMSTE } \\
\text { C/ }\end{array}$ & MIROC6 & $\mathrm{C}$ & $\mathrm{R}$ & $1.4^{\circ} / \mathrm{L} 81$ & $1^{\circ}, \mathrm{L} 62$ & $\mathrm{Y} / \mathrm{Y}$ & $\mathrm{A}, \mathrm{O}, \mathrm{I}$ & $\begin{array}{l}\text { A for } \\
\text { Ocean; } \\
\text { FF for Ice }\end{array}$ & $\begin{array}{l}\text { Nov of } \\
\text { each } \\
\text { year }\end{array}$ & 10 & 10 \\
\hline NIES & & & & & & & & & & & \\
\hline
\end{tabular}




\begin{tabular}{|c|c|c|c|c|c|c|c|c|c|c|c|}
\hline $\mathrm{CMCC}$ & CMCC-CM2-SR5 & $\mathrm{C}$ & $\mathrm{R}$ & $1^{\circ} / \mathrm{L} 30$ & $1^{\circ} / \mathrm{L} 50$ & $\mathrm{Y} / \mathrm{Y}$ & $\begin{array}{l}\mathrm{A}, \mathrm{L}, \\
\mathrm{O}, \mathrm{I}\end{array}$ & $\mathrm{FF}$ & $\begin{array}{l}\text { Nov of } \\
\text { each } \\
\text { year }\end{array}$ & 10 & 10 \\
\hline CMA & BCC_CSM_MR & $\mathrm{C}$ & $\mathrm{R}$ & $1^{\circ} / \mathrm{L} 46$ & $1^{\circ} / \mathrm{L} 40$ & $\mathrm{Y} / \mathrm{Y}$ & $\mathrm{O}$ & A & $\begin{array}{l}\text { Nov of } \\
\text { each } \\
\text { year }\end{array}$ & 10 & 10 \\
\hline CSIRO & CAFE & $\mathrm{C}$ & $\mathrm{R}$ & $20 / \mathrm{L} 24$ & $\begin{array}{l}10 \\
\text { /L506 }\end{array}$ & $\mathrm{Y} / \mathrm{Y}$ & $\mathrm{A}, \mathrm{O}$ & $\mathrm{FF}$ & $\begin{array}{l}\text { Each } \\
\text { month }\end{array}$ & 11 & 2 \\
\hline $\begin{array}{l}\text { European } \\
\text { EC-earth } \\
\text { consortiu } \\
\mathrm{m}\end{array}$ & EC-Earth3 (BSC) & NWP & $\mathrm{R}$ & $1 \%$ L91 & $1^{\circ} / \mathrm{L} 75$ & $\mathrm{Y} / \mathrm{Y}$ & $\begin{array}{l}\mathrm{A}, \mathrm{L}, \\
\mathrm{O}, \mathrm{I}\end{array}$ & $\mathrm{FF}$ & $\begin{array}{l}\text { Nov of } \\
\text { each } \\
\text { year }\end{array}$ & 10 & 10 \\
\hline $\begin{array}{l}\text { European } \\
\text { EC-earth } \\
\text { consortiu } \\
\mathrm{m}\end{array}$ & $\begin{array}{l}\text { EC- } \\
\text { Earth3(BSC/SMHI/ } \\
\text { DMI) }\end{array}$ & $\mathrm{C}$ & $\mathrm{R}, \mathrm{O}$ & $1 \%$ L91 & $1^{\circ} / \mathrm{L} 75$ & $\mathrm{Y} / \mathrm{Y}$ & $\begin{array}{l}\mathrm{A}, \mathrm{L}, \\
\mathrm{O}, \mathrm{I}\end{array}$ & $\begin{array}{l}\text { Two } \\
\text { versions: } \\
\text { FF (BSC) } \\
\text { and AI } \\
\text { (SMHI/D } \\
\text { MI) with } \\
\text { A for } \\
\text { Ocean/Ice } \\
\text {; FF for } \\
\text { Atm/Land }\end{array}$ & $\begin{array}{l}\text { Nov of } \\
\text { each } \\
\text { year }\end{array}$ & 10 & 10 \\
\hline INM & INM-CM5 & $\mathrm{C}$ & $\mathrm{R}$ & $2^{\circ} / \mathrm{L} 73$ & $\begin{array}{l}0.5^{\circ} / \\
\mathrm{L} 40\end{array}$ & $\mathrm{Y} / \mathrm{Y}$ & $\mathrm{A}, \mathrm{O}$ & A & $\begin{array}{l}\text { Nov of } \\
\text { each }\end{array}$ & 10 & 10 \\
\hline $\begin{array}{l}\text { LASG/IA } \\
\mathrm{P}\end{array}$ & FGOALS-g3 & $\mathrm{C}$ & $\mathrm{R}$ & $2^{\circ} / \mathrm{L} 26$ & $1^{\circ}, \mathrm{L} 30$ & $\mathrm{Y} / \mathrm{Y}$ & $\mathrm{O}$ & $\mathrm{FF}$ & $\begin{array}{l}\text { Nov of } \\
\text { each } \\
\text { year }\end{array}$ & 10 & 10 \\
\hline $\begin{array}{l}\text { LASG/IA } \\
\mathrm{P}\end{array}$ & FGOALS-f3 & $\mathrm{C}$ & $\mathrm{R}$ & $1^{\circ} / \mathrm{L} 32$ & $1^{\circ}, \mathrm{L} 30$ & $\mathrm{Y} / \mathrm{Y}$ & $\mathrm{O}$ & A & $\begin{array}{l}\text { Nov of } \\
\text { each } \\
\text { vear }\end{array}$ & 10 & 10 \\
\hline MPI & MPI-ESM-HR & $\mathrm{C}$ & $\begin{array}{l}\mathrm{R}, \mathrm{O} \\
\text { (via }\end{array}$ & $1^{\circ} / \mathrm{L} 95$ & $\begin{array}{l}0.4^{\circ} \\
/ \mathrm{L} 40\end{array}$ & $\mathrm{Y} / \mathrm{Y}$ & $\begin{array}{l}\mathrm{A}, \mathrm{L}, \\
\mathrm{O}, \mathrm{I}\end{array}$ & $\begin{array}{l}\text { A for } \\
\text { Ocean/Ice } \\
\text { :FF for }\end{array}$ & $\begin{array}{l}\text { Nov of } \\
\text { each }\end{array}$ & 10 & 10 \\
\hline
\end{tabular}




\begin{tabular}{|c|c|c|c|c|c|c|c|c|c|c|c|}
\hline & & & DWD) & & & & & atm & year & & \\
\hline MRI & MRI-ESM2 & $\mathrm{C}$ & $\mathrm{R}$ & $1^{\circ} / \mathrm{L} 80$ & $\begin{array}{l}1 \times 0.5^{\circ} / \mathrm{L} \\
60\end{array}$ & $\mathrm{Y} / \mathrm{Y}$ & $\mathrm{O}$ & A & $\begin{array}{l}\text { Nov of } \\
\text { each } \\
\text { year }\end{array}$ & 10 & 10 \\
\hline NCAR & CESM1 & $\mathrm{C}$ & $\mathrm{R}$ & $\begin{array}{l}0.9^{\circ} \times 1.25^{\circ} \\
\text { / L } 30\end{array}$ & $\begin{array}{l}0.25^{\circ} \\
\text { Tropics } \\
/ 1^{\circ} \\
\text { global/ } \\
\text { L60 }\end{array}$ & $\mathrm{Y} / \mathrm{Y}$ & $\mathrm{O}$ & $\mathrm{FF}$ & $\begin{array}{l}\text { Nov of } \\
\text { each } \\
\text { year }\end{array}$ & 40 & 10 \\
\hline $\mathrm{NCC}$ & NorCPM1 & $\mathrm{C}$ & $\mathrm{R}$ & $2^{\circ} / \mathrm{L} 26 \mathrm{~L}$ & $1^{\circ} / \mathrm{L} 53$ & $\mathrm{Y} / \mathrm{Y}$ & $\mathrm{O}$ & A & $\begin{array}{l}\text { Nov of } \\
\text { each } \\
\text { year }\end{array}$ & 10 & 10 \\
\hline UKMO & DePreSys4 & $\mathrm{C}$ & $\mathrm{R}, \mathrm{O}$ & $\begin{array}{l}0.5^{\circ} \times 0.8^{\circ} / \\
\text { L85 }\end{array}$ & $\begin{array}{l}0.25^{\circ} \\
/ \mathrm{L} 75\end{array}$ & $\mathrm{Y} / \mathrm{Y}$ & $\mathrm{A}, \mathrm{O}, \mathrm{I}$ & FF & $\begin{array}{l}\text { Nov of } \\
\text { each } \\
\text { year }\end{array}$ & 10 & 10 \\
\hline
\end{tabular}

1678

1679 